\title{
A Practical Load Disaggregation Approach for Monitoring Industrial Users Demand with Limited Data Availability
}

\author{
Sara Tavakoli ${ }^{1,2}$ (D) and Kaveh Khalilpour ${ }^{2, *(\mathbb{D})}$ \\ 1 Iran Grid Management Company, Tehran 1996836111, Iran; s.tavakoli555@gmail.com \\ 2 Faculty of Engineering and IT, University of Technology Sydney, Sydney, NSW 2007, Australia \\ * Correspondence: Kaveh.Khalilpour@uts.edu.au; Tel.: +61-2-9514-5744
}

Citation: Tavakoli, S.; Khalilpour, K. A Practical Load Disaggregation Approach for Monitoring Industrial Users Demand with Limited Data Availability. Energies 2021, 14, 4880. https://doi.org/10.3390/en14164880

Academic Editor: Javier Contreras

Received: 2 July 2021

Accepted: 5 August 2021

Published: 10 August 2021

Publisher's Note: MDPI stays neutral with regard to jurisdictional claims in published maps and institutional affiliations.

Copyright: (c) 2021 by the authors. Licensee MDPI, Basel, Switzerland. This article is an open access article distributed under the terms and conditions of the Creative Commons Attribution (CC BY) license (https:// creativecommons.org/licenses/by/ $4.0 /)$.

\begin{abstract}
The emergence of smart sensors has had a significant impact on the utility industry. In particular, it has made the planning and implementation of demand-side management (DSM) programmes easier. Nevertheless, for various reasons, some users may not implement smart meters for load monitoring. This paper addresses such cases, particularly large-scale industrial users, which, despite heavy electrical loads coming from many different processes, implement only simple energy measuring equipment for billing purposes. This necessitates the utilisation of novel methodologies for load disaggregation, often referred to as nonintrusive load monitoring (NILM). The availability of such tools can create multifold benefits for industrial park management, utility service providers, regulators, and policymakers. Here, we introduce an optimisation algorithm for nonintrusive load disaggregation that is low-cost, speedy, and acceptably accurate. As a case study, we used real network data of three industrial sectors: food processing, stonecutting, and glassmaking. For all cases, the optimisation framework developed a desegregated profile and estimated the load with an error of less than $5 \%$. For non-workdays, given the higher uncertainty for the continuity of different processes, the estimation error was higher but still in an acceptable range of around 3.63-15.09\% with an average of $8.10 \%$.
\end{abstract}

Keywords: nonintrusive load monitoring; load disaggregation; industrial load; demand-side management (DSM)

\section{Introduction}

\subsection{Industrial DSM and the Need for Load Disaggregation}

Demand-side management (DSM) is a powerful tool to change the load curve to achieve a more reliable, efficient, and secure power grid [1] while increasing consumers' benefits [2]. This can be done by playing the role of different operating reserve forms, which can reduce the need for overinvestment in generation capacity and improve the utilisation factor of the existing generators, altogether leading to a reduced cost of delivered electricity for customers. This is essential considering that the average generation capacity utilisation is less than $65 \%$ in some cases, and the load of transmission lines is below $39 \%$ [3] (the load of transmission lines is below 50\% at peak time to secure network safety in the case of parallel line outages [4]). There are different types of DSM programmes, including demand response, power delivery efficiency, HVAC improvement, distributed energy storage, and energy efficiency [1,5]. Each of these programmes may perform differently for a specific customer segment, given the diversity of their electricity consumption pattern. For instance, load shifting is a feasible DSM approach for households. In the domestic sector, while there are different patterns and appliances in different countries [6], generally, some loads such as washing machines, vacuum cleaners, irons, and pool pumps are considered flexible for time-shifting with minimal impact on user comfort. In contrast, some other loads such as fridges, TV, and computers should be considered inflexible for time-shifting to maintain customer comfort [7]. To provide appropriate DSM programmes 
for the domestic sector, smart sensor data and diaries of appliances are needed. Yet, these are not always available, especially in developing countries. In these cases, interviews may be helpful [6]. Commercial customers use much higher power than households, and most of them have a relatively constant power consumption pattern [1]. Generally, commercial load characteristics make load shifting an inappropriate option since it interferes with regular commercial business. For these customers, DSM solutions such as HVAC control or energy storage systems installation can be more suitable $[1,5]$. Comparing the three sectors of households, commercial businesses, and industries, as discussed earlier, for the first two sectors, load curve reshaping is possible with HVAC and lighting control systems or appliance time-shifting, although commercial businesses are less flexible than households. Nevertheless, the critical concern is the power-intensive industrial sector with various manufacturing levels [8]. As such, the industrial DSM requires the integration of production and energy management programmes and a detailed consumption data analysis for developing DSM programmes tailored for each category. The key concern is that, generally, utility's DSM-related measurement equipment involves massive data collection and handling, which reduces industrial business owners' interests in DSM programmes [9]. They are usually concerned that DSM programmes may affect their core business and that the revenue stream is highly dependent on external factors like the results of electricity market actions. These concerns are more serious when decision-makers are not experts in DSM [10]. Most studies in industrial DSM programmes target one industry. As a part of an industrial project, they collect huge data with the permission of the industry owner to study possible DSM programmes. Furthermore, in these cases, a change of processes may be proposed, which is not necessarily the best choice regarding other factors such as activity duration extension [11]. However, these ad hoc projects cannot be used for industrial park energy or on a larger scale such as regulation and policymaking. In large projects, industry owners are not usually willing to share data, and this is a great challenge. However, the results of large projects provide data to identify the process with the most impact and define incentives to make a big change in the industry. When there is a lack of access to disaggregated load data from different production lines of an industrial complex, DSM programme development becomes reliant on high-level coarse data points. This implies the need for methodologies to synthesise disaggregated load using bulk data.

\subsection{Load Disaggregation Approaches}

According to Gaur, "nonintrusive load monitoring (NILM) is a single-channel blind source separation problem, where the smart meter is the only channel that reads the total power consumption, and the problem is to find the power consumption of individual appliances. This means that there is a single observation (smart meter reading) and many variables (appliances); this is a highly underdetermined problem and, hence, impossible to solve directly" [12]. Hart [13] introduced nonintrusive appliance load monitoring in 1992 by measuring the current and voltage of the total domestic load. It was a revolutionary idea in the load monitoring field since it did not require the installation of sensors on appliances, which are both expensive and intrusive to the owner's privacy. He also explained that two types of nonintrusive signatures, i.e., steady-state signature and transient signature, help load disaggregation. Since then, there have been several studies on different aspects of NILM. Norford and Leeb [14] studied commercial loads, dealing with challenges such as loads turning on and off simultaneously, changing transient power patterns, and the tendency of commercial users to make the load more resistive to reduce the bill for reactive power. It is worth mentioning that not all NILM methods are entirely nonintrusive. Some researchers used intrusive methods for training their algorithms by having at least one sensor for each appliance to measure the current during the training period [15]. According to Farinanccio and Zmeureanu [15], steady-state signatures are enough for modelling most residential appliances due to at least three advantages. First, considering the continuous state of the appliance leads to easier detection of changes. Second, in any state transition cycle, the sum of the power changes is zero. Third, when two appliances are activated, 
their steady-state values are summed. Such results are very promising for the facilitation of DSM. The reason is that, although transient-based methods or steady-state/transient methods $[16,17]$ are undeniably more efficient, they require the installation of new and expensive sensors, while steady-state sensors are usually preinstalled for billing purposes. In addition, while preinstalled sensors in commercial and industrial sectors measure active and reactive power or current and voltage, there are only active power measurement sensors in the domestic sector. As such, steady-state solutions attract more customers toward DSM programmes.

Moreover, the electricity bill reduction behaviour of the commercial and the industrial business owner through power angle modification makes reactive power monitoring unreliable in the commercial and the industrial sector. Thus, an active-power-based NILM method seems pretty useful, as implemented by some researchers, such as Devlin and Hyes [18] and Baranski [19]. Baranski [19] used a genetic algorithm to optimise the on or off state of appliances for load disaggregation of active power consumption with $1 \mathrm{~s}$ sample time for domestic load with no training requirement. The training requirement determines the level of collaboration needed from the place owner; hence, the method should be chosen wisely on the basis of the owner's willingness to share data and collaborate.

In more recent years, some studies attempted to improve load disaggregation precision by analysing different signals and features like current waveform, active/reactive power, harmonics, instantaneous admittance waveform, instantaneous power waveform, eigenvalues, and switching/transient waveform. While most studies chose one feature (e.g., Suzuki et al. [20] studied current waveform), some others (e.g., Liang et al. [21]) studied all of them. The study used multiple algorithms and improved the result precision by at least $10 \%$ compared to single-feature and single-algorithm methods. Other studies, such as the one by Green et al. [22], used multiscale multialgorithm frameworks to present widely used methods. Nevertheless, it should be considered that a more general solution with multialgorithm calculation may need more processes, meaning a more expensive solution that may not be necessary or rational in some practical cases. Further detailed information about studies in this field may be found in previous review papers [23-25]. Nevertheless, given that the majority of studies address domestic NILM, these review papers were more focused on domestic loads. There are limited studies that addressed commercial NILM (e.g., [14,26,27]) or industrial NILM (e.g., [28-32]) to help the implementation of DSM programmes in these sectors. Laughman et al. [28] used a high-resolution, $8000 \mathrm{~Hz}$ field monitoring system to analyse both active and reactive power for industrial load disaggregation. They carried out higher harmonic and transient studies, but they did not provide numerical data from their research output. A few years later, Chang et al. [29] published a study focused on industrial load disaggregation. They studied the voltage and current waveforms to identify steady-state and transient signatures. They used the highest sample rate, $15,000 \mathrm{~Hz}$, for their research and reported $95.3 \%$ accuracy in their results. After a decade, in 2018, Martins et al. [30] proposed a deep learning algorithm for industrial load disaggregation. Using only active power with $1 \mathrm{~Hz}$ resolution for factory load disaggregation, they proved that their algorithm results in more accurate results in most cases compared to the factorial hidden Markov model (FHMM). They reported accuracy between $90.84 \%$ and $98.52 \%$. Brucke et al. [31] used the particle swarm optimization algorithm to disaggregate the load of an industrial building. They used active and reactive power data with $1 \mathrm{~Hz}$ resolution and reported a $6.92-13.72 \%$ error in active power estimation. The most recent research in this field was published by Yang et al. [32]. They used the active and reactive power of a factory with a sample rate of $1 \mathrm{~Hz}$ for their study. Using FHMM, they disaggregated the load of five pieces of industrial equipment. They showed that using FHMM with both active and reactive power provided 52.36-96.99\% accuracy, but using only active power decreased the accuracy to $40.86-96.99 \%$.

Table 1. Industrial load disaggregation presents a summary of industrial load disaggregation studies. 
Table 1. Industrial load disaggregation studies.

\begin{tabular}{llll}
\hline Study & Case Study & Variables & Sample Rate (Hz) \\
\hline Laughman et al. [28] & An industrial building & The active and reactive power & 8000 \\
Chang et al. [29] & An industrial building & $\begin{array}{l}\text { The voltage and current waveforms in a three-phase } \\
\text { electrical service }\end{array}$ & 15,000 \\
Martins et al. [30] & One factory & The active power & 1 \\
Brucke et al. [31] & An industrial building & The active and reactive power & 1 \\
Yang et al. [32] & One factory & The active and reactive power & 1 \\
\hline
\end{tabular}

As seen in Table 1, the previous studies used high-resolution meters that are not always available. Furthermore, four of the five studies used reactive power or voltage and current data, which are useful only in the location of the industrial load. These data are defective at any bulk point due to power factor equipment usage in the industry sector to avoid paying for reactive power. In addition, when one factory or an industrial building is studied, the owners are usually collaborative in the training phase; however, in larger projects, industrial secrecy is a great challenge. These three challenges highlight a research gap that this study aimed to fill.

\subsection{Industrial DSM Projects across the World}

There are many DSM projects and studies completed or in progress in various countries, which studied the main sectors, i.e., the domestic, commercial, and industrial sectors. Generally, they showed the high potential or main problems in industrial DSM programmes. There are also some studies that solely focused on the industrial sector's DSM programmes. For instance, run-of-river hydropower plants have the largest share in the Nepal electricity generation combination, leading to problems in the dry season. Moreover, there is a low annual and daily load factor, making DSM mandatory. A DSM study in 2006 suggested installing one intelligent controller for each $9.4 \mathrm{~kW}$ motor for power factor correction in the industrial sector, making up about 32\% of peak demand load (150 MW), which could lead to $63 \mathrm{MW}$ load reduction potential in 2015 [33]. In 2011, a team studied the possibility of DSM implementation in the energy-intensive industries of Germany [34]. The outcome identified the potential to provide $50 \%$ of territory reserve capacity through DSM in six energy-intensive industries. These six sectors were selected on the basis of total electricity consumption and the electricity costs per gross value added in each sector. Naturally, high consumption and high costs are expected to create a motivation for industrial owners to make interferences in their production processes.

India has the third largest transmission network globally, facing many challenges, including supply shortfalls, high network losses (26\% of production), power theft (24\% of production), and inefficiency in metering and revenue collection, which increase the motivation for DSM. A study in 2014 revealed that mid-term and long-term load forecasts have a significant role in DMS, and sector-wise studies and the efficiency of the technologies are essential in this regard, especially in agriculture and small-scale industry sectors which are heavily subsidised [35]. Warren [36] reviewed the UK's DSM policies and stated that the UK has interruptible/curtailment contracts with large industries with a minimum power of $3 \mathrm{MW}$ to provide $1.5 \mathrm{GW}$ of DSM capacity during peak time.

Alasseri et al. [37] reviewed DSM implementation strategies in Kuwait through incentive-based demand response programmes. As "one of the highest per capita electricity consumption and $\mathrm{CO}_{2}$-emitting countries in the world", DSM is in great need in Kuwait. However, the high subsidisation of electricity (94\%) makes consumers unmotivated for price-based demand response programmes. According to the study, incentive-based demand response programmes can be implemented successfully in residential and commercial loads. However, the industrial sector is challenging due to very low energy prices, whereby "any investment to enhance electricity conservation will have a long payback period" [37]. Industrial energy demand accounts for the largest energy consumption share (around 31\%) [38]. Another study investigated the DSM implementations in China's ongo- 
ing power sector reform [39]. According to the study, the Chinese government requires "manufacturing facilities to adjust production shifts, businesses to stagger working hours, and industrial facilities to perform equipment maintenance and conduct employee training during peak seasons or peak hours". Nevertheless, it is expected that this method might result in high economic costs.

There are extensive global efforts for DSM implementations. For instance, the International Energy Agency's (IEA) 2020 report on demand response provided more examples of DSM projects across the world [40]. The cases discussed above are just a highlight of the importance of DSM programmes in the industrial sector and the potential role of NILM in DSM programmes. Although the industrial load disaggregation literature is steadily growing, there exist many challenges yet to be overcome. In summary, the following are some such challenges to be addressed:

- In contrast to domestic equipment, which typically includes household appliances (e.g., fridge, TV, and washing machines), equipment types vary greatly in different industries [9]. As such, the domestic load disaggregation methods may fail when applied to the industrial sector. This necessitates a unique load analysis for any given industry.

- As there are more diverse load types in the industrial sector than in the domestic sector, the logical assumption of a unique signature for a given load in the $\Delta \mathrm{P}-\Delta \mathrm{Q}$ plane may not be valid for the industrial user [28]. When there are only active power data available, as there is no $\Delta Q$ axis, the risk of having the same points for different appliances is much higher. Hence, load identification accuracy decreases.

- In the industrial sector, electrical energy consumption is not separable from the flow of raw materials, intermediate materials, water, and gas [41]. Moreover, minimum intermediate material storage is important in industries. Thus, the sequence of processes may be considered. As the energy consumption of processes is linked, limits on any form of input energy or water may add constraints to the problem.

- Factory operation is a real-time process involving paid workers with a strict timeline [41]. As also discussed earlier, according to the experience from China [39], mandatory off-hours reduce manpower efficiency and, thus, increase costs.

- It is difficult, and in some cases impossible, to install smart meters for all houses [42]. Dynamic measurement is much more difficult for the industrial sector. Hence, highresolution data are not always available to offer disaggregated load information or enable disaggregation calculations.

- Given that factories pay for both active and reactive power consumption, they are motivated to use equipment for power factor adjustment, such as capacitors. As a result, reactive power cannot be used as additional data.

- Industrial secrecy is a severe challenge [9]. Industrial owners are very likely to be unwilling to share data, install meters, and fill diaries. Motivations are even less in countries with low industrial energy prices such as Kuwait [37] and India [35]. In most cases, there are only bulk point data available, which precludes the use of efficient load modelling algorithms such as smart meter-based methods [15,26,43-45], appliance feature-based methods [17,19,43-49], or methods needing training [28,29,50]. Furthermore, the limited methods addressing industrial NILM [27-29] may not be useful since they need high-frequency data acquisition.

- In most cases, providers have only bulk point data with low-resolution time steps (e.g., $15 \mathrm{~min}$ or more), which are installed for billing purposes. The installation of more accurate equipment is unattractive due to costs. As a consequence, transient state methods $([14,16,50])$ become useless in these cases.

In this paper, a new method for industrial load disaggregation is proposed to address the above challenges in response to the high potential of the industrial sector for DSM programmes and the lack of a proper method regarding the above challenges. The proposed method is based on a few facts and assumptions: First, industrial energy consumption and production are linked. Second, industrial activities rely on paid workers, and any load change impacts 
manpower costs. Third, detailed measured data and industrial owner cooperation are not available. Fourth, industrial processes are rather continuous and have a relatively fixed duration. Figure 1 shows a summary of the unique features of industrial load in the context of opportunities, treats, and solutions provided in the developed method.

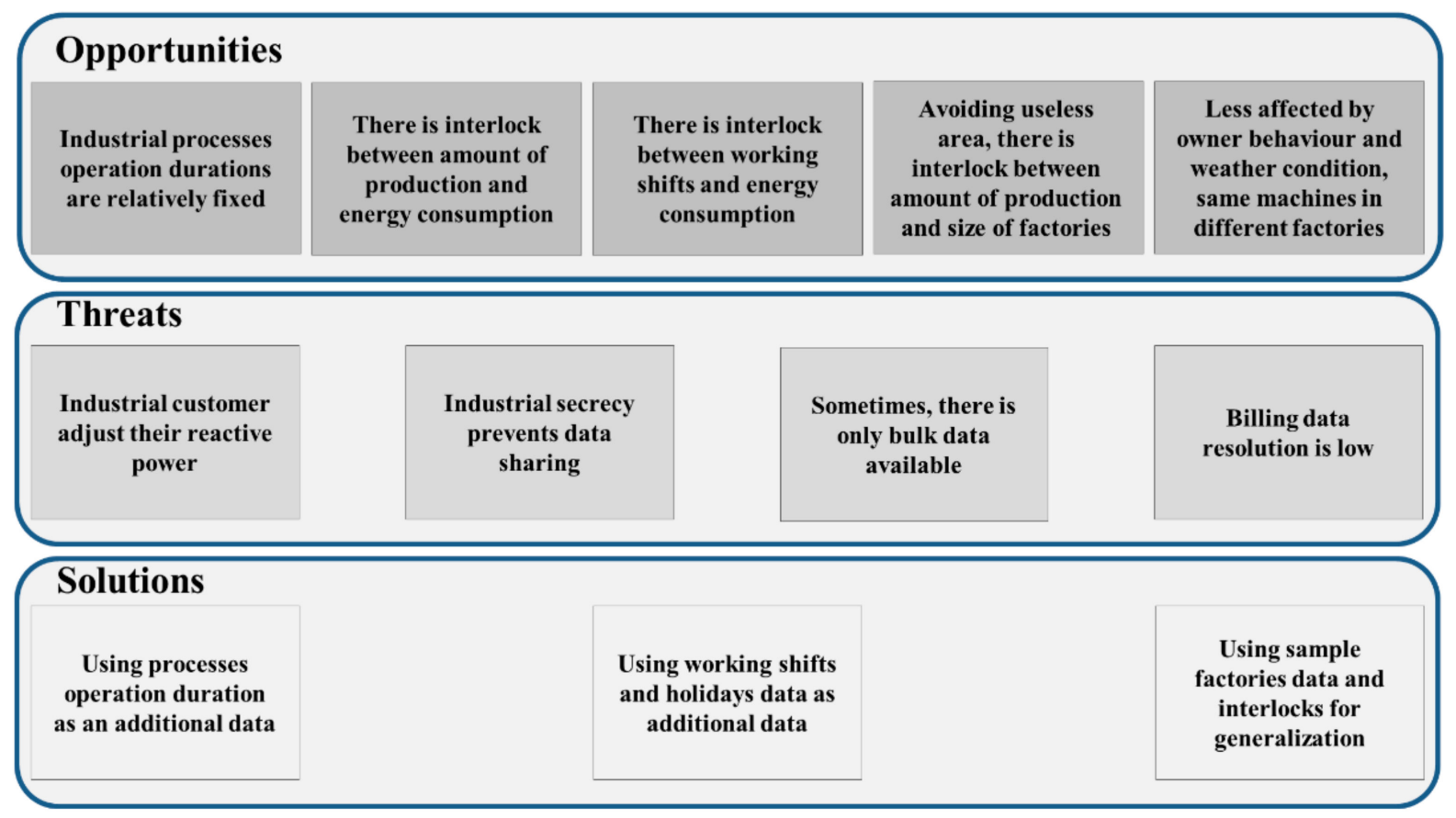

Figure 1. Industrial load features and solutions to overcome threats using opportunities.

The novelties and main contributions of this study are listed below.

- Using industrial process operation duration as additional data in load disaggregation instead of reactive power, current waveform, or other electrical features used in previous studies;

- Using energy consumption-material production and energy consumption-manpower links in industrial load disaggregation;

- Providing acceptable results with low-resolution input data (hourly data in day study horizon).

This method's effectiveness has been proven using real data collected from an industrial zone substation. The next section is dedicated to the methodology. In the third section, the case studies are discussed, followed by a discussion and conclusion.

\section{Industrial Load Disaggregation Methodology}

The challenge of limited data recording for industrial loads (e.g., only active power data) was elaborated in the previous section. This paper, however, aims to assess the utilisation of some unique features in the industrial loads, which might enable load disaggregation even with incomplete data. For instance, while household data depend highly on resident behaviour, for the industrial sector, the process duration is relatively fixed. Industries may be categorised into three groups by energy consumption pattern: (1) short process manpower-based industries (SPM), (2) constant energy demand industries (CED), and (3) combined energy demand pattern industries (CEDP). Each of these categories and the possible strategies for their load disaggregation are discussed next, with a comparison of key similarities or differences provided in Table 2. 
Table 2. Industry group properties.

\begin{tabular}{|c|c|c|c|c|c|}
\hline & $\begin{array}{l}\text { Processes Take a Few } \\
\text { Hours or Can Be Split } \\
\text { into a Few Hours }\end{array}$ & $\begin{array}{l}\text { Processes Are } \\
\text { 24/7 Activities }\end{array}$ & $\begin{array}{c}\text { Processes } \\
\text { Demand Manpower }\end{array}$ & $\begin{array}{c}\text { The Energy } \\
\text { Consumption Curves } \\
\text { Show Increases and } \\
\text { Decreases Linked to } \\
\text { Working Shift Hours }\end{array}$ & $\begin{array}{c}\text { The Energy } \\
\text { Consumption Curves } \\
\text { Show Energy } \\
\text { Consumption on } \\
\text { Weekends and Off-Days }\end{array}$ \\
\hline SPM & $\checkmark$ & $x$ & $\checkmark$ & $\checkmark$ & $x$ \\
\hline CED & $x$ & $\checkmark$ & $x$ & $x$ & $\checkmark$ \\
\hline CEDP & $\checkmark$ & $\checkmark$ & $\checkmark$ & $\checkmark$ & $\checkmark$ \\
\hline
\end{tabular}

\subsection{Industry Groups}

\subsubsection{Short Process Manpower (SPM) Industries}

For the industries in this category, major processes take a few hours, and it is possible to split the activities of these industries into segments a few hours long. Manpower is a critical factor in SPM industry energy consumption patterns. Processes start and finish by the start and end of working shifts. The start time and duration of processes are impacted by weekdays, the start and end of daily working hours, and lunch/rest hours. The features of the SPM category are as follows:

- Most processes take a few hours or can be split into a few hours.

- Most processes demand manpower to conduct or supervise the activity (sporadic processes such as slowly warming or cooling materials do not need manpower).

- The energy consumption curves show increases and decreases that can be linked to working shift hours.

Therefore, modelling the load pattern of SPM requires the incorporation of the industry manpower schedule, as outlined below.

- $\quad$ Generate the weekly energy consumption curves (electricity and/or gas).

- Distinguish weekdays and weekends or public holidays, noting that different countries and cultures have different weekends or public holidays. Weekends for industries vary from 0-2 days across the world, often happening from Friday to Sunday. Even within a country, there might be multiple time zones, and different states might have their own public holidays.

- Determine daily shifts. Increases and decreases in the daily energy consumption curve are very helpful in this case.

- Once the working shift schedules are identified, the next step would be the identification of process schedules and their consequent load. The following questions can help at this stage:

- Processes taking time more than one working shift: The inquiry here would be to determine whether such processes can split to fit completely in daily working shifts. If so, the start and end times of such processes can be fixed.

- A process requiring less time than a full working shift: In such cases, the processes would be assumed to begin sometime after the shift start time to be finished before the end of shifts.

- Consider working hour duration. If the process duration is the same as the working hour, there is no need to define the start time. The start time and the end time of the process are the same as daily working hours. If the process duration is less than the working hour duration, the start time is defined so that the process starts and ends during working hours. If the process duration is longer than the working hour duration, the start time may be any time up to $24 \mathrm{~h}$.

\subsubsection{Constant Energy Demand (CED) Industries}

For the industries in this category, major processes have 24/7 activities with constant energy demand. It is much easier to disaggregate load for this category of industries 
since there is no need to determine active hours for most processes. The industries in this category hold the following features:

- Most of the processes are 24/7 activities.

- The energy consumption curves show a "reasonable amount" of load on weekends or public holidays, which implies the continual operation of some processes. The "reasonable amount" implies that the baseload demand is much greater than nonindustrial energy consumption in the zone, for example, lighting energy consumption.

Once a CED industry is recognised, the following steps can be taken for load disaggregation, where some steps are identical to the SPM case:

- Form the weekly energy consumption curves (electricity and/or gas).

- Distinguish weekdays and weekends or public holidays.

- Determine the weekly holiday energy consumption. There should not be a significant variation in weekly holiday energy consumption. Otherwise, the industry's off-days have not been determined correctly.

- Once the working shift schedules are identified, the following questions can help further specify the schedule of processes:

- Baseload operations: Identify activities that cannot be stopped even for a short period and consider them constant loads.

- Interruptible processes: For a process that can pause their operation, if they are manpower-reliant, they can be assumed to start after shifts start to be finished before the end of shifts. Otherwise, they can have a start time any time within a day $(24 \mathrm{~h})$.

\subsubsection{Combined Energy Demand Pattern (CEDP) Industries}

While the first two categories are determined by their dominant features, some industries do not have either of these characteristics. CEDP industries include different processes with different durations. While there may be a short period of manpower-based processes or non-stoppable processes, there may also be long period processes that are stoppable. The industries in this category hold the following features:

- The industrial processes include both short and long period activities.

- The energy consumption curves show a reasonable amount of energy consumption difference in weekend and public holiday load, as well as during non-shift hours of weekdays.

- The energy consumption curves show increases and decreases that can be linked to shift hours.

When CEDP industries are recognised, disaggregation steps are the same as the SPM industry steps, but the third step of CED industries should also be taken into account. The following additional step specific for this category can be considered.

- Determine the difference between the weekly holiday energy consumption and the working day non-shift hours energy consumption. This amount is connected to long period processes. If it is relatively constant, there are $24 \mathrm{~h}$ but not $24 / 7$ activities and they are considered fixed consumption during the weekdays. Otherwise, any time within $24 \mathrm{~h}$ may be the start time.

Each category requires its own set of data, including the industrial zone's total energy consumption curve and the identification of all active industry processes in the zone and each activity level. Due to the reasons elaborated in the introduction, access to this amount of data is not often possible. The practical option is to wisely select a few industries to represent (1) the majority of industrial operation types and (2) the industrial zone as a whole. 


\subsection{Industry Energy Consumption Evaluation}

In this section, we introduce unique methodologies for each of the three industry categories discussed earlier.

\subsubsection{SPM Industry: Machine-Based (MB) Method}

In some industries, electrical machines are the primary means of processes. Machines have rating power consumption, assuming that they are usually used at the rated capacity and under-capacity usage does not significantly decrease energy consumption. Field studies such as [51] have shown that there is usually more than one machine for each process in a factory. When factories work under capacity, they prefer to use one machine at full capacity instead of two machines at half capacity because industrial machines have better performance at a nominal rate. Moreover, this is more energy-efficient. Thus, generally, this assumption is acceptable. However, in some cases, it may be false and lead to estimation errors, which cannot be avoided due to limited data. The operation duration is fixed, and the average number of needed machines per fixed amount of product is determined. Hence, if the total product is estimated, the length and power demand of each process are determined. The procedure is described below.

First, the given factory's required machines need to be identified, and it is also determined whether the number of machines is dependent on the daily product. For dependent ones, the number of machines to produce one unit of product is given by

$$
m_{i, j, k}=M_{i, j, k} / p r_{j, k}
$$

where $m_{i, j, k}$ is the per-unit number of machines of $i$ process in $j$ factory in $k$ industry, $M_{i, j, k}$ is the number of machines, and $p r_{j, k}$ represents the daily product of $j$ factory in $k$ industry. For the independent scenario, the per-unit number of machines is equal to the number of machines, given by

$$
m_{i, j, k}=M_{i, j, k}
$$

Then, the average values are calculated as

$$
m_{i, k}=\frac{1}{n_{k}} \sum_{j}^{n_{k}} m_{i, j, k}
$$

where $n_{k}$ is the number of sample factories in industry $k$. The industry's total daily production using the total area allocated to the industry and daily product and area of sample factories can be calculated as follows:

$$
\begin{gathered}
\overline{p r}_{k}=\frac{1}{n_{k}} \sum_{j}^{n_{k}} \frac{p r_{j, k}}{A_{j, k}}, \\
\operatorname{Pr}_{k}=\overline{p r}_{k} * A_{k},
\end{gathered}
$$

where $\overline{p r}_{k}$ is the average daily product per unit of area in industry $k, A_{j, k}$ is the area of factory $j$ in industry $k, P r_{k}$ is the total daily production of industry $k$, and $A_{k}$ is the total area of industry $k$. The total number of factories in the zone is calculated using the total area allocated to the industry and the average area of single sample factories.

$$
\begin{gathered}
\bar{A}_{k}=\frac{1}{n_{k}} \sum_{j}^{n_{k}} A_{j, k}, \\
N_{k}=\frac{A r_{k}}{\overline{A r}_{k}},
\end{gathered}
$$

where $\bar{A}_{k}$ is the average area of factories in industry $k$, and $N_{k}$ is the total number of factories in industry $k$ in the case study zone. The total number of required machines is 
determined by the total daily product or the total number of factories. For dependent and independent machines, it is calculated by Equations (8) and (9), respectively.

$$
\begin{aligned}
M_{i, k} & =m_{i, j, k} P r_{k}, \\
M_{i, k} & =m_{i, j, k} N_{k},
\end{aligned}
$$

where $M_{i, k}$ denotes the total number of machines for process $i$ in industry $k$. The total needed power for each type of machine is calculated using the rated power of each machine.

$$
P_{i, k}=p_{i, k} M_{i, k}
$$

where $P_{i, k}$ is the total power consumed by process $i$ in industry $k$, and $p_{i, k}$ is the rated power of process $i$ of industry $k$. With this, we can form the load curve table containing the total power, $P_{i, k}$, and duration, $T_{i, k}$, of a process carried out by machines.

\subsubsection{CED Industry: Constant Working Equipment (CWE) Method}

These types of equipment include compressors, pumps, and coolers. The number of needed equipment or their total rated capacity depends on product volume. As there is no determined start time or duration, this method is easier. First, the equipment's total power consumption in sample factories is calculated as follows:

$$
P_{j, k}=\sum_{i} m_{i, j, k} p_{i, j, k}
$$

where $P_{j, k}$ is the total power consumed in industry $k$, and $p_{i, j, k}$ is the rated power of process $i$ in factory $j$ of industry $k$. Then, the average power demand per product is given by

$$
p_{k}=\frac{1}{n_{k}} \sum_{j}^{n_{k}} \frac{P_{j, k}}{p r_{j, k}},
$$

where $p_{k}$ is the average needed power per product in industry $k$, and $p r_{j, k}$ is the daily production of factory $j$ in industry $k$. The total product of the industry zone is calculated using Equations (4) and (5). The total consumed energy of the industry zone is given by

$$
P_{k}=P r_{k} p_{k}
$$

where $P_{k}$ is the total power consumed in industry $k$.

\subsubsection{CEDP Industry: Combined Energy Usage Pattern (CEUP) Method}

These types of industries usually include MB and CED steps. MB steps were discussed in Section 2.2.1, but there are modifications for CED steps if the processes need specific energy instead of specific power. Rated power is calculated using per-unit energy and time based on available data for processes.

$$
p_{i, k}=\frac{e_{i, k}}{T_{i, k}}
$$

where $p_{i, k}$ is the rated power of process $i$ in industry $k, e_{i, k}$ is the rated energy of process $i$ in industry $k$, and $T_{i, k}$ is the duration of the process $i$ in industry $k$. The industry's total daily production is calculated using the total area allocated to the industry, daily product, and area of sample factories according to Equations (4) and (5). The total power of each process in the industry zone is calculated using the total daily product and the rated power of the process.

$$
P_{i, k}=p_{i, k} \operatorname{Pr}_{k} .
$$

The load curve table is formed to show the total power, $P_{i, k}$ and duration, $T_{i, k}$, of a process done by machines. 


\subsection{Decomposition Challenges and Solutions}

The goal of this section is to decompose the industrial zone load curve. As mentioned in the introduction, there are limited (detailed) data available to use conventional methods. The power and duration of each process are available in addition to the total load curve. Load curves cannot be simply added to make up the main curve. Two main issues should be considered: industry factors and process start times.

Industry factors: In the last section, three different methods were studied, and it was assumed that companies in the same industry are relatively similar from a power consumption point of view. This assumption may not be precise, but some estimations help solve the problem with fewer data and cheaper measurement costs, making these assumptions acceptable. However, some assumptions are not acceptable. For example, there may be empty fields in the area that is dedicated to a particular industry in industrial zones or there may be built factories that are not in operation or that are operating at half load. In total industry calculations, using the area ratio, there was an assumption that the entire area is filled with factories operating at full load. Industry factors were introduced to modify this assumption. These factors are representative of the non-operation part of the industrial zone. In other words, they are derating factors for calculated power consumption. $\mathrm{Xu}$ [42] introduced "weighting factors" in his work that have relatively the same role as industry factors in this paper.

Process start time: Start times are defined for processes that take less than $24 \mathrm{~h}$, considering that there are processes that take $4,6,8$, or $12 \mathrm{~h}$. The key challenge is to predict their start time and to know whether they start concurrently or sequentially.

At this point, the theoretical power and duration of processes and the industrial zone's overall load curve are known. The real power and start time, industry factors, and start time should be determined to find actual process load curves. For this problem, the objective function is to minimise the difference between the actual load curve and the formed load curve. It is formulated as shown below

$$
\min \sum_{t=0}^{23}\left(P_{t}-\sum_{i} a_{i, k, t} P_{i, k} I F_{k}\right),
$$

where $P_{t}$ represents the industrial zone's power consumption over time (h) $t, a_{i, k, t}$ presents the status of the process ( 1 if the process $i$ is on or 0 otherwise), and $I F_{k}$ is the industrial factor. We used a time interval of $1 \mathrm{~h}$. However, when available, smaller time steps would be preferred to reduce prediction error.

Given that $a_{i, k, t}$ and $I F_{k}$ are variables, their multiplication converts the optimisation to a nonlinear problem. Therefore, other constraints should be considered and help to narrow down feasible space. Constraints include industrial factor constraints, start time constraints, and continuity constraints. Continuity constraints are not easy to formulate and need chained constraints to be defined, complicating their solution. In these cases, AI algorithms provide more convenient solutions. Hence, this study used an AI algorithm, the genetic algorithm, as done in some previous studies [17,44].

Industrial factor constraints limit industrial activity between no activities in the zone and the allocated zone's full activity. However, it can be limited further on the basis of additional data. For example, the total load curve value ratio to the calculated total load is the upper limit. Alternatively, if there are data available that a specific amount of product is produced, the lower limit can be increased.

$$
\max \left\{0, \frac{\min \left(P_{i, k}\left(P r_{k}\right)\right)}{\max \left(P_{t}\right)}\right\}<I F_{k} \leq \min \left\{1, \frac{\min \left(P_{t}\right)}{\min \left(P_{i, k, t}\right)}\right\} \quad \forall k
$$

where $\min \left(P_{i, k}\left(\operatorname{Pr}_{k}\right)\right)$ is the minimum value of total power of process $i$ in industry $k$ based on minimum production data. Other limits may be calculated and added using the zone's load curve characteristics. 
Start time constraints prevent answers indicating that the process is started during night hours for industries or other illogical answers depending on the total load curve. $a_{i, k, t}$ forms a vector for $24 \mathrm{~h}, a_{i k}$; however, considering that the process duration is fixed, knowing the start time determines the vector components. $b_{i k}$ is the start time, between 0 to 23 , that helps to form $a_{i k}$. It can be limited further by considering working shifts in industry or raw material flow in some cases.

$$
\begin{gathered}
0 \leq a_{i, k, t} \leq 1 \quad \forall a_{i, k, t} \in\{0,1\}, \\
X_{i, k}<b_{i, k}<Y_{i, k} \quad \forall b_{i, k} \in\{0,1,2, \ldots, 23\},
\end{gathered}
$$

where $b_{i, k}$ is the start time (h) of the process $i$ in industry $k$. The population consists of $n$ candidates (sum of the number of industries and processes) with the start times and the industrial factors formed as genotypes: $\left\{\mathrm{b}_{11}, \mathrm{~b}_{12}, \ldots, \mathrm{IF}_{1}, \mathrm{IF}_{2}, \ldots\right\}$. The first generation's genotypes are guessed. Fitness is evaluated as a function of the difference between the actual load curve and the formed load curve. The upper half of the population is chosen as next-generation parents with mutation steps for industrial factors and start times. The termination factor is reaching a specific number of generations. Figure 2 shows the method in graphical format.

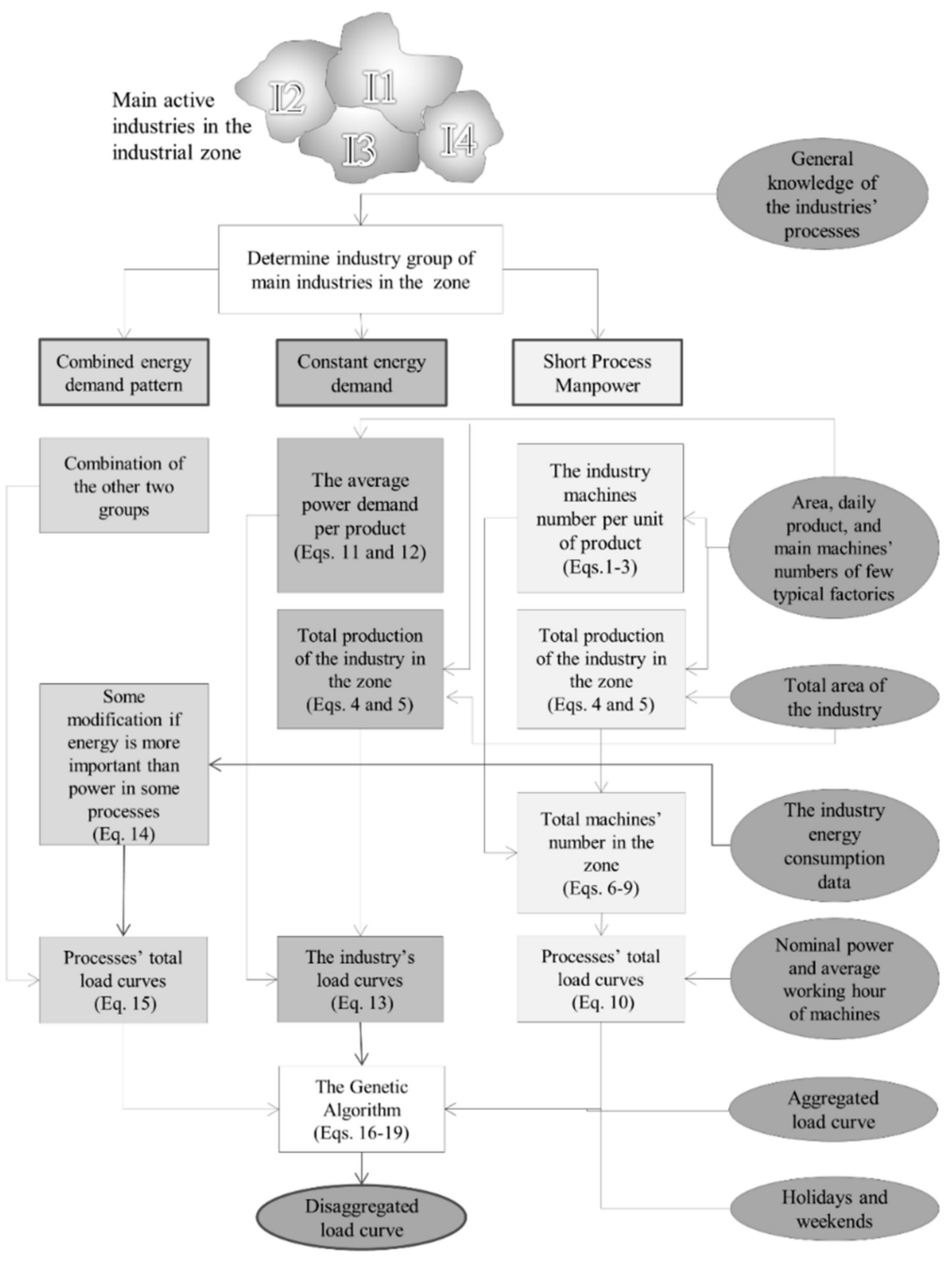

Figure 2. Graphical presentation of the proposed industrial load disaggregation algorithm.

\section{Case Studies}

As a case study of the presented formulation, we used the Shams Abad industrial zone, near Tehran, Iran, with major factories including food processing (7799 ha), stonecutting 
(1661 ha), and glassmaking (430 ha). We had access to the total hourly energy (active power) consumption of this industrial zone. Figure 3 shows the hourly load curve of the Shams Abad industrial zone in spring over a week. As such, we utilised the presented algorithm to decompose this industrial zone's load curve.

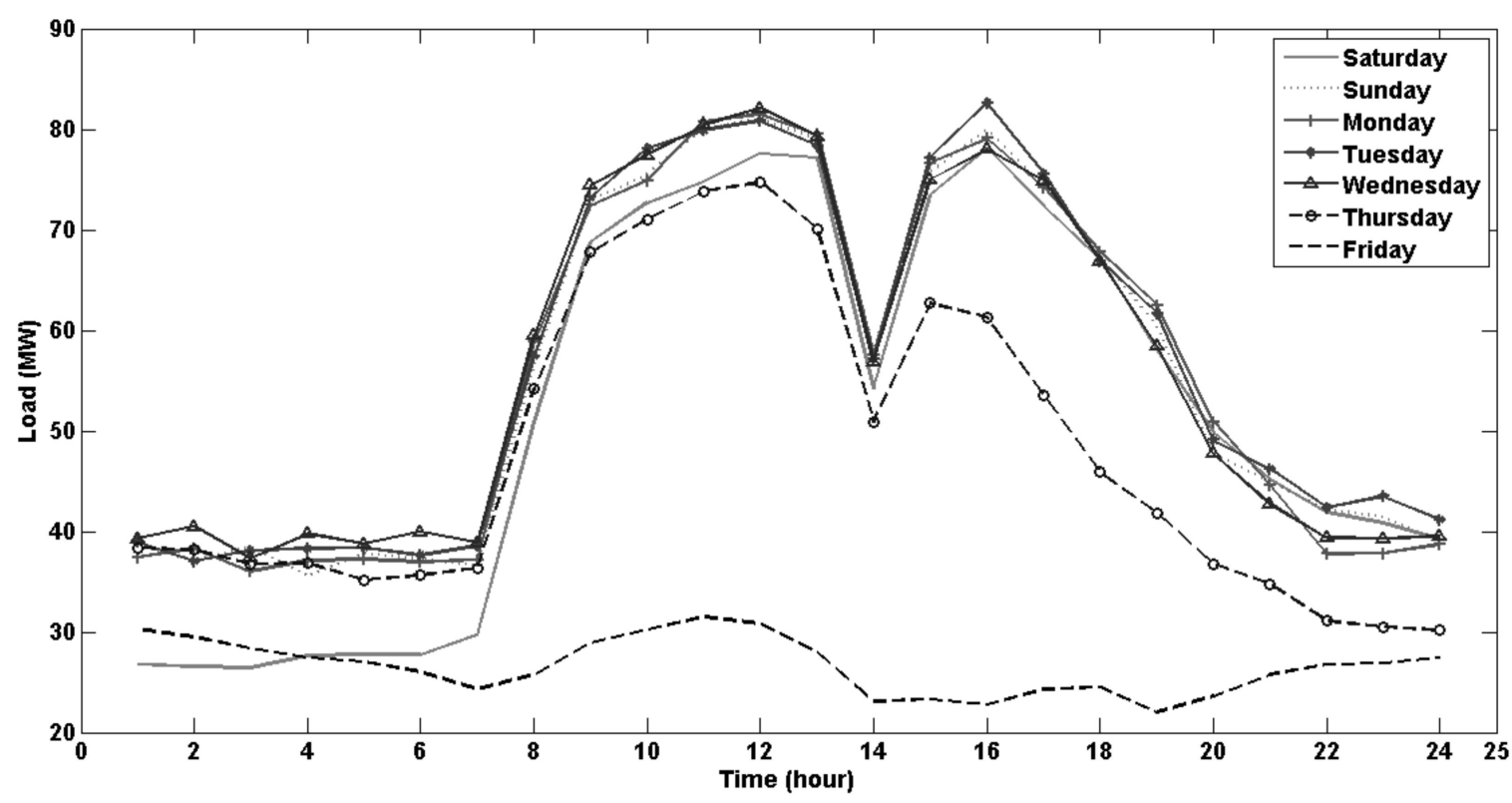

Figure 3. Hourly load curve of Shams Abad industrial zone in spring over a week.

For each industry, energy-consuming processes are discussed to determine the industry's group and industry energy consumption according to the earlier definitions. Of the three main industries in Shams Abad, the glass industry also features three different products (containers, flat glass, and fibreglass) with different energy consumption patterns. As such, our case studies included four factories: stonecutting, food (cold storage), glass containers, and flat glass, as discussed next.

\subsection{Stonecutting Industry}

Stonecutting is an energy-intensive industry. The average electrical energy consumption varies for different types of stones with, for instance, the values being 13.4, 8.5, and $7.5 \mathrm{kWh}$ per square meter for granite, marble, and travertine. As it is hard to determine each manufacturer's products, average numbers were used in this study.

This industry's main stages are cutting stone coops (extracted stone from the mine), polishing, and cutting to proper sizes. The block cutting machine is the main machine in each stonecutting factory responsible for the main costs and energy consumption. There are single-blade and multi-blade types of these machines. A single-blade tip cutting machine makes a 30-60 cm deep cut each time. Multi-blade machines, with up to 80 blades, have the same depth of cut. They can make multiple cuts at the same time, but it takes much longer for them to cut [51]. The polishing machines have multiple electric motors. Each head moves in a rotatory manner and polishes the stone. Then, there are length-cutting and width-cutting machines that cut the stone to desired sizes.

All three characteristics of the SPM energy consumption pattern (See Section 2.1.1) are recognised in this industry; hence, the MB method (See Section 2.2.1) was implemented. First, it was essential to determine the average number of machines. Table 3 shows machine data based on a survey in Esfahan, Iran [51]. Iran, Italy, India, and Brazil are the largest stone producers in the world [52]. 
Table 3. Stonecutting machines number based on data from 10 Iranian stonecutting factories.

\begin{tabular}{|c|c|c|c|c|c|c|c|}
\hline Manufacturer & $\begin{array}{l}\text { Daily Product } \\
\quad\left(\frac{m^{2}}{h a . d a y}\right)\end{array}$ & Block Cutting (No.) & $\begin{array}{l}\text { Block Cutting per } \\
\text { Daily Product } \\
\left(\frac{N o .}{m^{2} . d a y}\right) \times 10^{3}\end{array}$ & $\begin{array}{c}\text { Polishing } \\
\text { Machine (No.) }\end{array}$ & $\begin{array}{l}\text { Length Cutting } \\
\text { Machine (No.) }\end{array}$ & $\begin{array}{c}\text { Width } \\
\text { Cutting } \\
\text { Machine (No.) }\end{array}$ & $\begin{array}{c}\text { Width } \\
\text { Cutting per } \\
\text { Daily Product } \\
\left(\frac{N o .}{m^{2} . d a y}\right) \times 10^{3}\end{array}$ \\
\hline 1 & 300 & 2 & 6.67 & 1 & 1 & 3 & 10 \\
\hline 2 & 200 & 2 & 10 & 1 & 1 & 2 & 10 \\
\hline 3 & 250 & 2 & 8 & 1 & 1 & 1 & 4 \\
\hline 4 & 300 & 3 & 10 & 1 & 1 & 2 & 6.67 \\
\hline 5 & 120 & 1 & 8.33 & 1 & 1 & 1 & 8.33 \\
\hline 6 & 100 & 1 & 10 & 1 & 1 & 2 & 20 \\
\hline 7 & 130 & 2 & 15.4 & 1 & 1 & 1 & 7.7 \\
\hline 8 & 200 & 1 & 5 & 1 & 1 & 1 & 5 \\
\hline 9 & 100 & 1 & 10 & 1 & 1 & 2 & 20 \\
\hline 10 & 110 & 1 & 9.1 & 1 & 1 & 1 & 9.1 \\
\hline
\end{tabular}

Table 3 reveals that manufacturers have only one polishing machine and one lengthcutting machine regardless of their production capacity (independent machines), while the numbers of block-cutting and width-cutting machines vary, and we can assume them as dependent machines. For such machines, their required amounts were calculated using Equations (1)-(3).

Other machines include cranes, water pumps, calibrations for thickness adjustment, resins for warming and gluing porous stones, middle cutters, and dryers. Not all manufacturers own all of these machines, but their energy consumption is not negligible. For a typical middle-sized stonecutting factory, other machines with a total rated power of $80 \mathrm{~kW}$ for $1-10$ motors are operated between 1 and $24 \mathrm{~h}$ a day [51]. It was assumed that each factory has five machines with an average power of $16 \mathrm{~kW}$ working for $12 \mathrm{~h}$.

As there are not enough data available for Shams Abad stonecutting, the data collected from some similar Iranian stonecutting factories were used to calculate the total daily product, see Table 4 . The average daily production of the stonecutting industry was calculated using Equation (4). The total daily product was calculated using Equation (5).

Table 4. Data for Iranian stonecutting factories.

\begin{tabular}{cccc}
\hline Manufacturer & $\begin{array}{c}\text { Daily Product } \\
\left(\mathbf{m}^{\mathbf{2}} / \mathbf{d a y}\right)\end{array}$ & Area $\left(\mathbf{A}_{\mathbf{j}, \mathbf{s}}\right) \mathbf{( h a )}$ & $\begin{array}{c}\text { Per-Unit Daily } \\
\left.\text { Product }\left(\mathbf{p r}_{\mathbf{j}, \mathbf{s}}\right)\left(\mathbf{m}^{\mathbf{2}} / \mathbf{( d a y} \cdot \mathbf{h a}\right)\right)\end{array}$ \\
\hline 1 & 2092 & 2 & 1046 \\
2 & 418.12 & 2.3 & 181.79 \\
3 & 125.42 & 0.5 & 250.87 \\
4 & 125.43 & 0.5 & 250.87 \\
\hline
\end{tabular}

The technical data and daily working hours for stonecutting machines are shown in Table 5 [51]. According to Shams Abad industrial zone visits, each manufacturer's area is around 2.5 hectares, and the total area for the stonecutting industry was calculated using Equation (7) to be $1661 \mathrm{ha}$. The total number of machines in the zone was calculated using Equations (8) and (9). A table of stonecutting load curves was formed using Equation (10), see Table 6.

Table 5. Rated power and working hours of typical machines in a middle-sized stonecutting factory.

\begin{tabular}{ccc}
\hline Machine & Average Power (kW) & Daily Working Hours (h/day) \\
\hline Block cutting machine & 110 & 24 \\
Polishing machine & 11 & 8 \\
Length-cutting & 30 & 8 \\
Width-cutting & 4 & 8 \\
Other machines & 80 & 1-24 (considering the machine) \\
\hline
\end{tabular}


Table 6. Stonecutting load curves in Shams Abad (full-load assumption).

\begin{tabular}{ccc}
\hline Machine & Average Power (MW) & Daily Working Hours (h/day) \\
\hline Block cutting machine & 730.73 & 24 \\
Polishing machine & 7.304 & 8 \\
Length-cutting & 19.92 & 8 \\
Width-cutting & 2.656 & 8 \\
Other machines & 53.12 & 12 \\
\hline
\end{tabular}

\subsection{Food Industry (Cold Storage)}

Food industry factories in Shams Abad are mostly cold stores or meat and chicken packaging factories (with cold storage still representing their main energy consumption). Cold stores are an example of industries with relatively constant energy consumption. Compressors, evaporators, condensers, ammonium pumps, and water pumps form the primary energy consumption of cold stores with continuous operation. The only exception is the noncontinuous operation of forklifts for pallet movement. As such, cold stores satisfy the two defined features of the CED category; therefore, the CWE method can be implemented.

Given that the equipment of various cold stores is very similar, it is possible to generalise the energy consumption of various cold stores. As such, we used the data of the Noavaran cold store in the Shams Abad industrial zone, which has a total area of 14 hectares and a capacity of 80,000 tonnes. These data were gathered through its weblog, a site visit, and interviews.

With these descriptions, we could now apply the CWE method to this case. The first step was to determine the total energy consumption in the sample factory using Equation (11). The Noavaran cold store has eight compressors. The number of compressors, voltage, current, and power factor determine consumption. It is essential to consider that the capacity factor makes a difference in current amplitude. At any given time step, some evaporators and condensers are on, while some are off. Evaporators have 600 fans with only one-third of them operating at the same time. There are eight condensers, half of which are always off. Pumps work at full capacity and are always on. Compressors operate at $380 \mathrm{~V}, 0.93$ power factor, and $600 \mathrm{~A}$ at 0.44 of their capacity. Each evaporator fan consumes $1.5 \mathrm{~kW}$. Each condenser has $10 \mathrm{~kW}$ power consumption. There are four ammonium pumps with $15 \mathrm{~kW}$ electricity consumption for above-zero halls and two ammonium pumps with $3.5 \mathrm{~kW}$ electricity consumption for below-zero halls. Each of the two water pumps has a $3.5 \mathrm{~kW}$ power rating.

As compressors, evaporators, condensers, ammonium pumps, and water pumps are operating $24 / 7$, their electrical load was summed and considered as one constant load. For the forklifts, their technical data were considered. These data included the number of main and hydraulic motors and the power rating, as well as the charge and discharge time. The Noavaran cold store has ten 3 tonne forklifts manufactured by Sepahan Company, model SEM20. Each has three motors: two AC motors with $10 \mathrm{~kW}$ nominal power and one hydraulic $\mathrm{AC}$ motor with $24 \mathrm{~kW}$ nominal power. They take $8 \mathrm{~h}$ to fully charge and operate for $8 \mathrm{~h}$.

Knowing Noavaran's capacity of 80,000 tonnes, the average energy demand per product could be obtained from Equation (12). With that, while also considering the Noavaran cold store's area of 14 hectares and the total area of 7799 ha dedicated to the food industry, the total energy consumption of the industrial zone was calculated using Equations (4), (5), and (13). With this, the food industry load curve table was formed (Table 7).

Table 7. Food industry load curves in Shams Abad (full-load assumption).

\begin{tabular}{ccc}
\hline Food Industry Load & Average Power (MW) & Daily Working Hours (h/day) \\
\hline Constant load & 1175.6 & 24 \\
Variable load & 13.37 & 8 \\
\hline
\end{tabular}




\subsection{Glass Container Industry}

The glass industry's primary energy-consuming processes are batch preparation/ formulation, melting/refining, forming, and post-forming. Batch preparation involves mixing raw materials to create a particular type of glass. This process includes moving raw materials from storage silos to adjacent weigh hoppers, leading to improved quality of the mixture and reducing energy consumption for batch preparation and formulation. Then, the materials are transported by conveyor belts to mixers to be prepared for the next stage. The next process is melting, which is carried out in three steps: melting raw materials into a homogeneous liquid, refining the step by removing bubbles from the melted batch, and eliminating thermal and chemical variations from the molten glass. The last step requires cooling tanks. Some heat should be applied to the molten glass in this step to cool it uniformly. For glass containers, tanks have melting areas of $60-180 \mathrm{~m}^{2}$, which deliver 100-500 tonnes/day of glass. The forming and post-forming processes include different methods, for example, blow and blow or press and blow methods for containers. Forming consumes about $12-33 \%$, and post-forming consumes about $11-18 \%$ of total energy consumption [53].

All three characteristics of CEDP were recognised in this industry; thus, the CEUP method was implemented. Among glass container manufacturers in this industrial zone, the Nouri Taze Company is a relatively big one ( $72 \mathrm{ha}$ ) with more available data. If there are large-scale factories such as Nouri Taze with accessible data, their own data can be used for more accurate calculations. However, usually, there are not enough data available; hence, estimation methods are used. The industrial zone has 27 other glass container companies and 12 flat glass companies. Given the 430.1 ha area of the glass industry, and assuming that the companies other than Nouri Taze have a relatively similar area, the dedicated area for the glass container industry was estimated to be $320 \mathrm{ha}$. The daily product level per area is culture-based. Thus, while estimation may be used, it is better to use local data averages. Table 8 lists the data of the four Iranian glass container manufacturers.

Table 8. Iranian glass container manufacturer data.

\begin{tabular}{cccc}
\hline Manufacturer & Daily Product ${ }^{\mathbf{1}}$ (tonne/day) & Area (ha) & $\begin{array}{c}\text { Per-Unit Daily } \\
\text { Product (tonne/(day.ha)) }\end{array}$ \\
\hline Nouri Taze & 183 & 72 & 2.55 \\
2 & 237 & 49.2 & 4.81 \\
3 & 65 & 9 & 7.20 \\
4 & 250 & 40 & 6.25 \\
\hline
\end{tabular}

${ }^{1}$ Considering 5.5 working days in a week, meaning 300 working days per year.

The Nouri-Taze per unit daily product was seemingly an outlier and was not involved in the average calculation. However, as Nouri Taze was a big company in our case study, its data were used for its calculations. The total daily product was calculated using Equations (4) and (5). Nouri Taze's daily production was added to that.

As mentioned in Section 2.2.3, some processes need specific energy instead of specific power. Specific energy consumption is used as an indicator of energy use per (physical) unit of output [54]. The second column of Table 9 shows specific energy consumption (including both heat and electricity), and the third column shows electrical energy consumption for the glass container manufacturing process [55]. The manufacturing energy and carbon footprints for the glass and glass products sector prepared for the US Department of Energy, Advanced Manufacturing Office by Energetics confirm these values [56]. Batching and preparation take about $4 \mathrm{~h}$. Melting is a continuous activity as it is not efficient to turn off furnaces. Forming glass containers with the individual section Owens Illinois machine takes $1 \mathrm{~min}$ for 500 bottles. Each container is $250 \mathrm{~g}$. According to Nouri Taze data, forming takes $6 \mathrm{~h}$. Post-forming varies wildly, and it was assumed to take $4 \mathrm{~h}$ on average. The total electricity consumption for each process was calculated using Equation (14) (see the fourth column of Table 9). The rated powers of processes were calculated using Equation (15). 
The last two columns show the glass container industry load curve data in Shams Abad (full-load assumption).

Table 9. The glass container industry load curves in Shams Abad (full-load assumption).

\begin{tabular}{cccccc}
\hline Process & $\begin{array}{c}\text { Average Specific Energy } \\
\text { Use }^{\mathbf{1}} \mathbf{( 1 0}^{\mathbf{6}} \mathbf{B t u} / \text { tonne) }\end{array}$ & $\begin{array}{c}\text { Average Specific } \\
\text { Electricity Use } \\
\mathbf{( 1 0}^{\mathbf{6}} \text { Btu/tonne) }\end{array}$ & $\begin{array}{c}\text { Rated Power } \\
\text { (MW/tonne) }\end{array}$ & $\begin{array}{c}\text { Total Power } \\
\text { (MW) }\end{array}$ & $\begin{array}{c}\text { Process Duration } \\
\text { (hr) }\end{array}$ \\
\hline Batching & $0.27-1.2$ & 0.53 & 0.0388 & 57.14 & 4 \\
Melting & 5.5 & 0.825 & 0.0101 & 14.88 & 24 \\
Forming & 0.4 & $0.4^{2}$ & 0.0195 & 28.72 & 6 \\
Post-Forming & 1.86 & 0.23 & 0.0169 & 24.89 & 4 \\
\hline
\end{tabular}

${ }^{1}$ Electricity use based on a conversion factor of $3412 \mathrm{Btu} / \mathrm{kWh} .{ }^{2}$ Forming does not use much heat [55].

\subsection{Flat Glass Industry}

The preparation and formation stages are the same as the glass container industry; however, in the melting/ refining stage, due to higher quality requirements, tanks have areas of $200-500 \mathrm{~m}^{2}$ with a capacity of 300-800 tonnes/day. The total area dedicated to the glass container and flat glass industry is $110.1 \mathrm{ha}$. The daily product level per area is culture-based. Thus, while estimation may be used, it is better to use local data averages. Table 10 shows a few Iranian flat glass manufacturers daily product and area data.

Table 10. Iranian flat glass manufacturer data.

\begin{tabular}{cccc}
\hline Manufacturer & Daily Product $^{\mathbf{1}}$ (tonne/day) & Area (ha) & Per-Unit Daily Product (tonne/(day.ha)) \\
\hline 1 & 900 & 75 & 12 \\
2 & 200 & 1.8 & 114.3 \\
3 & 400 & 30 & 13.3 \\
\hline
\end{tabular}

${ }^{1}$ Considering 5.5 working days in a week, meaning 300 working days per year.

The total daily product was calculated using Equations (4) and (5). The second column of Table 11 shows specific energy consumption (including both heat and electricity), and the third column shows electrical energy consumption for the glass container manufacturing process [55]. The manufacturing energy and carbon footprints for the glass and glass products sector report prepared for the US Department of Energy, Advanced Manufacturing Office by Energetics confirm these values [56].

Table 11. The flat glass industry load curves in Shams Abad (full load assumption).

\begin{tabular}{|c|c|c|c|c|c|}
\hline Process & $\begin{array}{l}\text { Average Specific Energy Use }{ }^{1} \\
\left(10^{6} \mathrm{Btu} / \text { tonne }\right)\end{array}$ & $\begin{array}{l}\text { Average Specific Electricity } \\
\text { Use }^{1}\left(10^{6} \mathrm{Btu} / \text { tonne }\right)\end{array}$ & $\begin{array}{l}\text { Rated Power } \\
\text { (MW/tonne) }^{1}\end{array}$ & Total Power (MW) & Process Duration (h) \\
\hline Batching & $0.27-1.2$ & 0.27 & 0.0198 & 101.44 & 4 \\
\hline Melting ${ }^{2}$ & 6.5 & 0.845 & 0.0103 & 52.91 & 24 \\
\hline Forming ${ }^{3}$ & 1.5 & 1.5 & 0.0366 & 187.85 & 12 \\
\hline Post-Forming 4 & 2.06 & 0.15 & 0.0110 & 56.36 & 4 \\
\hline
\end{tabular}

${ }^{1}$ Electricity use based on a conversion factor of $3412 \mathrm{Btu} / \mathrm{kWh} .{ }^{2}$ Considering regenerative side-port furnace. ${ }^{3}$ Forming does not use much heat [55]. ${ }^{4}$ Including annealing, laminating, and autoclave.

Batching and preparation take about $4 \mathrm{~h}$. Melting is a continuous activity as it is not efficient to turn off furnaces. Forming flat glasses takes $1 \mathrm{~min}$ for glass with a thickness of $2.5 \mathrm{~cm}$, a width of $3 \mathrm{~m}$, and a length of $96 \mathrm{~cm}$ with a typical glass. Glass density is $2.5 \mathrm{~g} / \mathrm{cm}^{3}$; thus, the rate of flat glass production for each machine is $180 \mathrm{~kg} / \mathrm{min}$. There are 20 manufacturers with two forming machines each and a total production of 5127.78 tonnes/day. Hence, forming takes about $12 \mathrm{~h}$. Post-forming varies greatly, and it was assumed to take $4 \mathrm{~h}$ on average.

The total electricity consumption for each process was calculated using Equation (14) (see the fifth column in Table 11). The rated powers of processes were calculated using 
Equation (15). The last two columns show the flat glass industry load curve data in Shams Abad (full-load assumption)

\subsection{Decomposition of Load Curves}

As discussed in 2.3, industry factors should be determined. Four industries were studied as representatives of all industries and companies in the field, thus leading to four industry factors. Processes that take less than $24 \mathrm{~h}$ need a starting time. There should be 11 start time variables, considering Tables 6, 7,9 and 11. This increases the number of variables to 15 . For defining the upper and lower limits of these 15 variables, we used the historical load data (Figure 3) with the following reasoning:

- Friday's load curve was relatively constant. In Iran, weekends are Thursday and Friday. This was related to a constant load, including glass melting and the cold store's constant load, which helped in calculating the maximum industry factor for the industries with a constant load.

- Saturday's load curve until 7 a.m. was similar to Friday's. Other manpower-demanding processes do not begin until 8 a.m. on the first working day of the week.

- Thursday's evening load curve implies the inactivity of some industries.

- There were valleys in the load curves from 1-3 p.m. due to the inactivity of manpowerbased processes during the lunch break. This separated the working hours into two periods from 9 a.m. to 1 p.m. and from 3 p.m. to 5 p.m. Therefore, it was reasonable to consider stonecutting as a two-part process, instead of an $8 \mathrm{~h}$ process.

- The load curves of Sunday to Wednesday were similar, and the average load curve was used to reduce the calculation burden. The average peak load in the week helped to calculate the maximum industry factor for the industries.

- There was a difference between weekend night load and weekday night load. This difference likely resulted from a $24 \mathrm{~h}$ process that did not need to continue.

Using these data and Equation (17), upper and lower limits were determined.

\subsubsection{Upper Limits Using the Minimum Value of the Zone's Load Curve}

The comparison of the weekend's constant load compared with the industries' constant loads helped to find maximum industry factors. In this case study, Friday's load, 26.62 MW, resulted from the constant load of the glass melting and food industries. This helped to consider the maximum value for the glass and food industries using Equation (17) (IFfg, max < 0.4536, IFf, max < 0.0226). The glass container industry's calculated melting demand was less than Friday's load $(14.4<26.62)$; hence, it did not impose new constraints. The minimum power value of the stonecutting industry was zero due to the lack of continuous processes. The minimum power value of the food industry was the constant power, and the minimum power value of glass industries was the melting process power. The melting power of the flat glass industry and the constant power of the food industry were above the minimum value of the load curve. Thus, their upper limits were $1\left(\mathrm{IF}_{\mathrm{fg}, \max }<1\right.$, $\left.\mathrm{IF}_{\mathrm{f}, \max }<1\right)$.

\subsubsection{Upper Limits Using the Maximum Value of the Zone's Load Curve}

The average peak load of the week (in this case, $87 \mathrm{MW}$ ) was also valuable for upper limit determination. Simultaneous activities in the flat glass industry include melting, forming (12 h), and batching (the most energy-consuming process in the flat glass industry). This represents another way of calculating the flat glass industry's maximum industry factor. Comparing this result value with the value calculated in $\mathrm{A}$, the maximum value for the flat glass industry factor was 0.2542 .

Simultaneous activities in the glass container industry include melting and forming (the most energy-consuming process in the flat glass industry). This represents a way to calculate the glass container industry's maximum industry factor using Equation (17) (IFcg, max $<0.2875$ ). Considering that the forming process duration for flat glass is only $6 \mathrm{~h}$, there is no need to perform forming and batching or post-forming simultaneously. 
Furthermore, since this process consumes too much power, it is not reasonable to have another power-consuming process considering demand issues and equipment design. As no value was calculated in part $\mathrm{A}$, the maximum value for the glass container maximum industry factor was 0.2875 . Simultaneous activities in the food industry include constant load and variable load. Comparing the resulting value (IFf, $\max <0.0732$ ) with the value calculated in A, the maximum value for the food industry factor was 0.0226 .

\subsubsection{Upper Limits Using Curve Characteristics}

The difference in the night load of weekends and weekdays likely resulted from a $24 \mathrm{~h}$ interruptible processes, e.g., tip cutting. Thus, the stonecutting industry's maximum industry factor (IFsc, max < 0.0156) was calculated.

\subsubsection{Lower Limits Using the Maximum Value of the Zone's Load Curve}

In the food industry, the Noavaran factory with 80,000 tonnes of product leads to 2.11 MW constant load, but it does not operate at full capacity all the time. Hence, no lower limit was calculated. In the flat glass industry, the Nouri Taze factory with 183.33 tonnes of product per day led to a calculation of $1.85 \mathrm{MW}$. Table 12 shows upper and lower limits of industry factors that are added as constraints to the optimization problem.

Table 12. Upper and lower limits of industry factors.

\begin{tabular}{ccccc}
\hline Industry & $\begin{array}{c}\text { Flat Glass } \\
\text { Industry }\end{array}$ & Glass Container Industry & Food Industry & $\begin{array}{c}\text { Stonecutting } \\
\text { Industry }\end{array}$ \\
\hline Maximum IF & 0.2542 & 0.2875 & 0.0226 & 0.0156 \\
Minimum IF & - & 0.0212 & - & - \\
\hline
\end{tabular}

\section{Results}

It was assumed that the stonecutting process time is fixed. Other industry process start times should also be limited. Considering that load curves on weekdays increased at 8 a.m. and decreased at 9 p.m., these were set as the time limits for processes, with the exception of forklifts. This is a manpower-demanding process equivalent to the melting power of the flat glass industry. The charge time of forklifts is $8 \mathrm{~h}$, which allows $8 \mathrm{~h}$ of usage. They may be charged during the night or throughout the day. Drivers may work from 8 a.m. to 3 p.m.; accordingly, charging may start from as early as 4 p.m. Furthermore, 2 p.m. to 9 p.m. represents the latest shift available; thus, charging is expected to finish by 5 a.m., thereby establishing the charging range as 4 p.m. to 5 a.m. the next day. Table 13 shows upper and lower limits of start times in spring. The limitations are added to the optimization problem as constraints.

Table 13. The upper and lower limits of start times (in spring).

\begin{tabular}{ccccc}
\hline Industry & Process & Duration & Start Time Lower Limit & $\begin{array}{c}\text { Start Time } \\
\text { Upper Limit }\end{array}$ \\
\hline \multirow{3}{*}{ Flat glass } & Batching & 4 & 8 & 17 \\
& Forming & 12 & 1 & 9 \\
& Post-forming & 4 & 8 & 17 \\
\hline \multirow{3}{*}{ Glass container } & Batching & 4 & 8 & 17 \\
& Forming & 6 & 8 & 15 \\
& Post-forming & 4 & 16 & 17 \\
\hline Food industry & forklifts & 8 & & 29 \\
\hline
\end{tabular}

Many factories are closed or only open half-day on Thursdays. Friday is a public holiday, Saturday morning has a load similar to Friday, and Sunday-Wednesday have a typical weekday load. Thus, the algorithm should be separately applied to weekdays (Sunday to Wednesday), Thursday, Friday, and Saturday loads. As such, the optimisation 
programme was executed four times, and the results are demonstrated in Table 14 and Figure 4.

Table 14. The optimum value of the variables for various weekdays in a spring week.

\begin{tabular}{|c|c|c|c|c|}
\hline \multirow{2}{*}{ Variables } & \multicolumn{4}{|c|}{ Results for Various Weekdays } \\
\hline & Sunday-Wednesday & Thursday & Friday & Saturday \\
\hline Flat glass industry factor & 0.0998 & 0.0992 & 0.0992 & 0.0998 \\
\hline Glass container industry factor & 0.2114 & 0.2110 & 0.2110 & 0.2114 \\
\hline Stonecutting industry factor ${ }^{1}$ & 0.0147 & 0.0000 & 0.0000 & 0.01471 \\
\hline Food industry factor & 0.0169 & 0.0168 & 0.0168 & 0.0169 \\
\hline Batching, flat glass start time $(\mathrm{h})$ & 10 & 10 & - & 10 \\
\hline Forming, flat glass start time (h) & 8 & 8 & - & 8 \\
\hline Post forming, flat glass start time $(\mathrm{h})$ & 15 & 13 & - & 15 \\
\hline Batching, glass container start time $(\mathrm{h})$ & 9 & 9 & - & 9 \\
\hline Forming, glass container start time (h) & 15 & 8 & - & 15 \\
\hline Post forming, glass container start time $(\mathrm{h})$ & 13 & 15 & - & 13 \\
\hline Forklifts, food start time $(\mathrm{h})$ & 20 & 20 & - & 20 \\
\hline Estimation error $(\%)$ & 4.83 & 7.1 & 11.56 & 7.82 \\
\hline
\end{tabular}

${ }^{1}$ Block-cutting starts from 8 a.m. on Saturdays.

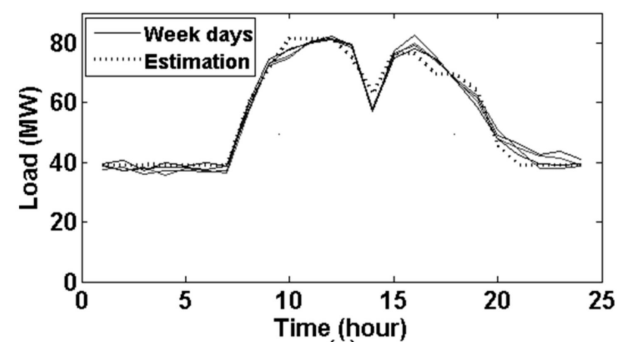

(a)

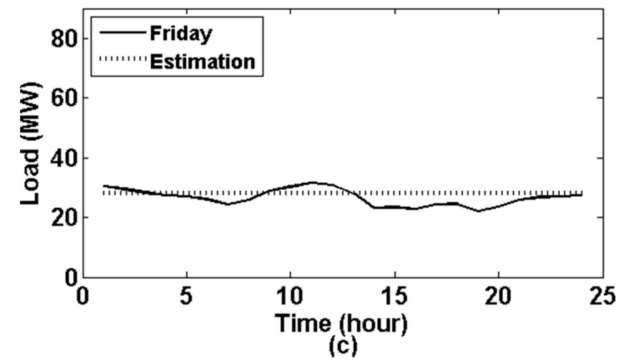

Figure 4. Estimated load curve vs. real load curve: (a) weekday (Sunday to Wednesday); (b) Thursday; (c) Friday; (d) Saturday.

As mentioned in Section 2.3, the genetic algorithm (GA) was used to solve the optimisation problem. The programming was conducted in the MATLAB environment. The objective function (Equation (16)) was to find the optimal value for process start times and industry factors with the least error between the target load curve and the estimated load curve. The codes' inputs included upper and lower limits of the process start times and industry factors (Equation (17)), as well as the target load curve. A set of random guesses within limitation boundaries formed the first-generation population. Equation (16) was used for sorting. At the beginning of each iteration, mutation was used for regenerating the lower half of the population. A group of children, representing up to 10\% of the main population, was created from the top $10 \%$ of the previous generation's genes. At the end of each iteration, $5 / 11$ of the upper population was saved to keep the population size fixed. The outputs included optimal process start times and industry factors, estimated load curve, and error percentage. 
Equation (20) was used for error calculation.

$$
\text { Error }=\frac{1}{24} \sum_{1} \frac{\left|\mathrm{P}_{1}-\overline{\mathrm{P}_{1}}\right|}{\mathrm{P}_{1}}
$$

The result showed a $4.83 \%$ error for weekday (Sunday-Wednesday) load estimation. Considering that hundreds of industrial zone processes were estimated using fewer than 20 processes, this can be considered high accuracy. The estimation error for Thursday was $7.1 \%$. The results show that the flat glass factories reduce their activity/production on Thursdays, and there are changes in working shifts, but there are no significant production changes. There are no changes in the food industry as expected, and stonecutting factories are closed. The main difference between the load curves of Saturday and of Sunday to Wednesday was noted between 1 a.m. and 7 a.m. The reasonable assumption is that a long process that is manpower-based is not carried out during the weekend and starts with the first working hour of the week's first working day. Block-cutting fits the features. The difference between the average load in hours 1 to 7 on Saturday and the other days was 11.1482 MW. Block-cutting consumption power, $730.73 \mathrm{MW}$, considering the stonecutting industry factor, 0.0147 , resulted in $10.74 \mathrm{MW}$, thereby verifying the assumption. The Friday load curve showed the minimum consumption. The assumption included the constant load of the food industry and the glass industry's melting load (uninterruptable loads). The result was 28.14 MW, which was close to the average Friday load of 26.62 MW.

The same method was used for load disaggregation of load curves for the different seasons. See Figure 5 and Table 15 for summer, Figure 6 and Table 16 for fall, and Figure 7 and Table 17 for winter.

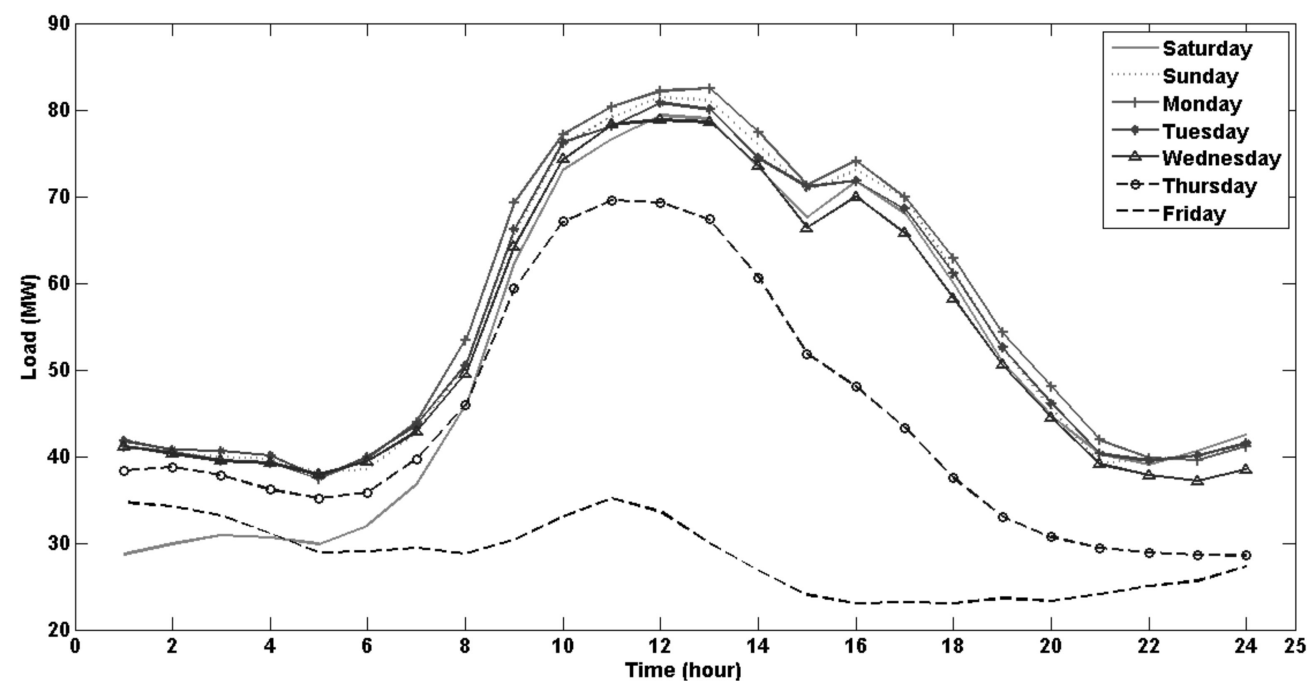

Figure 5. Hourly load curve of Shams Abad industrial zone in summer over a week.

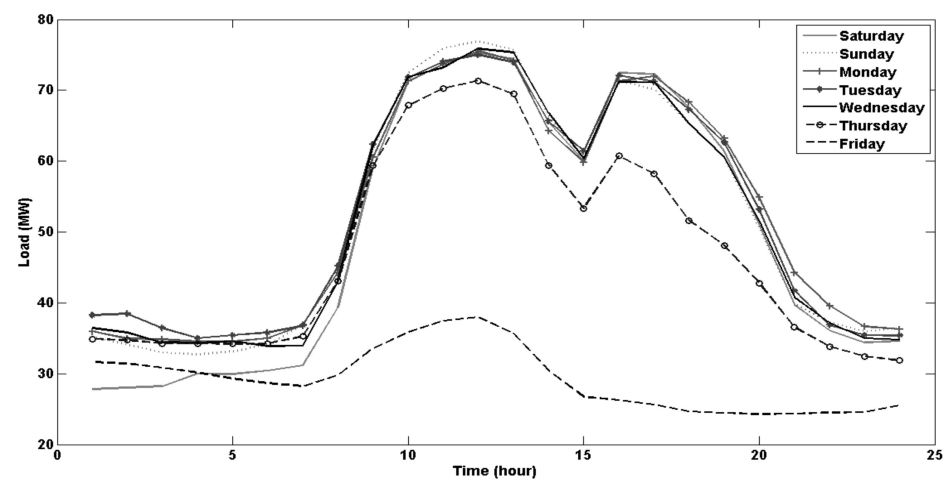

Figure 6. Hourly load curve of Shams Abad industrial zone in fall over a week. 
Table 15. The optimum value of the variables for various weekdays in a summer week.

\begin{tabular}{ccccc}
\hline Variables & \multicolumn{3}{c}{ Results for Various Weekdays } \\
\cline { 2 - 5 } & Sunday-Wednesday & Thursday & Friday & Saturday \\
\hline Flat glass industry factor & 0.0691 & 0.0653 & 0.0653 & 0.0691 \\
Glass container industry factor & 0.2752 & 0.2750 & 0.2750 & 0.2752 \\
Stonecutting industry factor 1 & 0.0150 & 0.0000 & 0.0000 & $0.0150 *$ \\
Food industry factor & 0.0184 & 0.0170 & 0.0170 & - \\
Batching, flat glass start time (h) & 14 & 14 & - & -0184 \\
Forming, flat glass start time (h) & 8 & 8 & - & 14 \\
Post forming, flat glass start time (h) & 13 & 12 & - & 13 \\
Batching, glass container start time (h) & 10 & 9 & - & - \\
Forming, glass container start time (h) & 9 & 8 & - & 15 \\
Post forming, glass container start time (h) & 15 & 20 & $10.51 \%$ & $3.41 \%$ \\
Forklifts, food start time (h) & 20 & $5.45 \%$ & & 20 \\
Estimation error (\%) & $3.62 \%$ & &
\end{tabular}

${ }^{1}$ Block-cutting starts from 8 a.m. on Saturdays.

Table 16. The optimum value of the variables for various weekdays in a fall week.

\begin{tabular}{|c|c|c|c|c|}
\hline \multirow{2}{*}{ Variables } & \multicolumn{4}{|c|}{ Results for Various Weekdays } \\
\hline & Sunday-Wed & Thursday & Friday & Saturday \\
\hline Flat glass industry factor & 0.0958 & 0.0956 & 0.0956 & 0.0958 \\
\hline Glass container industry factor & 0.1891 & 0.1885 & 0.1885 & 0.1891 \\
\hline Stonecutting industry factor ${ }^{1}$ & 0.0111 & 0 & 0 & 0.0111 \\
\hline Food industry factor & 0.0172 & 0.0172 & 0.0172 & 0.0172 \\
\hline Batching, flat glass start time (h) & 10 & 10 & - & 10 \\
\hline Forming, flat glass start time (h) & 9 & 9 & - & 9 \\
\hline Post forming, flat glass start time $(\mathrm{h})$ & 14 & 11 & - & 14 \\
\hline Batching, glass container start time $(\mathrm{h})$ & 16 & 8 & - & 16 \\
\hline Forming, glass container start time $(\mathrm{h})$ & 8 & 12 & - & 8 \\
\hline Post forming, glass container start time $(\mathrm{h})$ & 11 & 16 & - & 11 \\
\hline Forklifts, food start time (h) & 5 & 5 & - & 5 \\
\hline Estimation error (\%) & $3.1 \%$ & $6.81 \%$ & $15.09 \%$ & $3.69 \%$ \\
\hline
\end{tabular}

${ }^{1}$ Block-cutting starts from 8 a.m. on Saturdays.

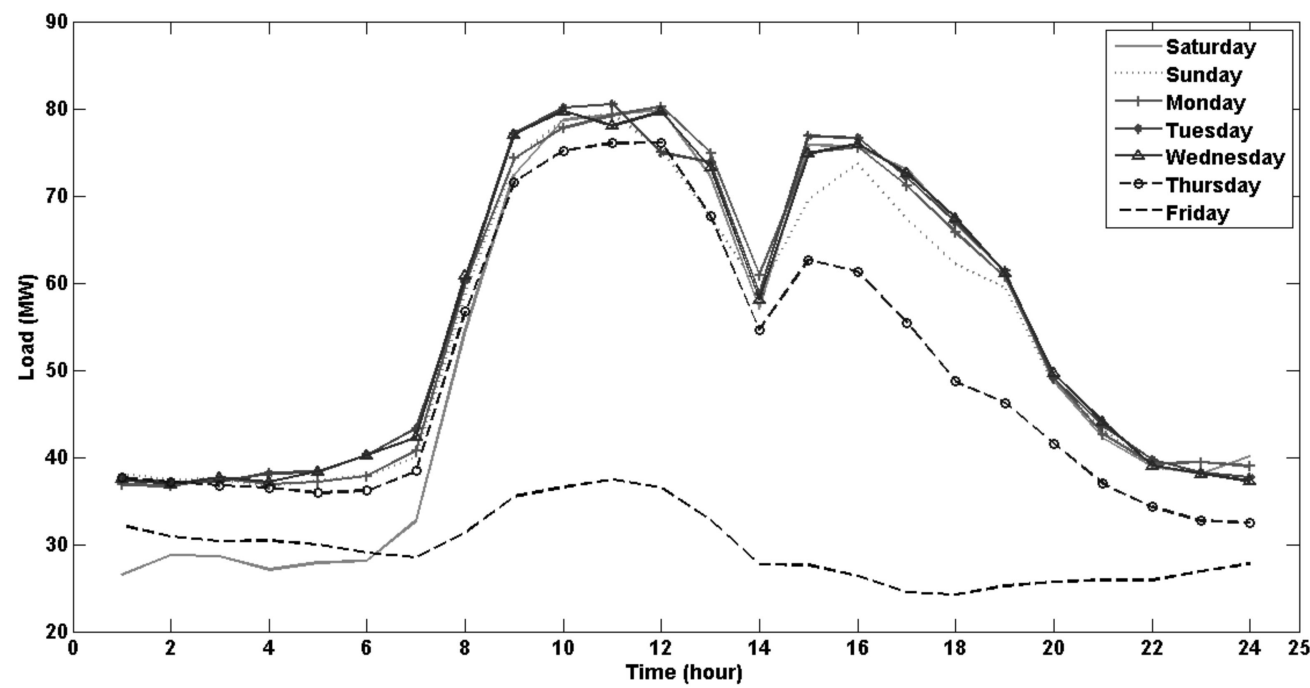

Figure 7. Hourly load curve of Shams Abad industrial zone in winter over a week. 
Table 17. The optimum value of the variables for various weekdays in a winter week.

\begin{tabular}{|c|c|c|c|c|}
\hline \multirow{2}{*}{ Variables } & \multicolumn{4}{|c|}{ Results for Various Weekdays } \\
\hline & Sunday-Wednesday & Thursday & Friday & Saturday \\
\hline Flat glass industry factor & 0.0881 & 0.0875 & 0.0875 & 0.0881 \\
\hline Glass container industry factor & 0.2313 & 0.2309 & 0.2309 & 0.2313 \\
\hline Stonecutting industry factor ${ }^{1}$ & 0.0144 & 0.0000 & 0.0000 & 0.0144 \\
\hline Food industry factor & 0.0177 & 0.0177 & 0.0177 & 0.0177 \\
\hline Batching, flat glass start time (h) & 10 & 10 & - & 10 \\
\hline Forming, flat glass start time (h) & 8 & 8 & - & 8 \\
\hline Post forming, flat glass start time (h) & 13 & 13 & - & 13 \\
\hline Batching, glass container start time $(\mathrm{h})$ & 9 & 9 & - & 9 \\
\hline Forming, glass container start time $(\mathrm{h})$ & 15 & 12 & - & 15 \\
\hline Post forming, glass container start time $(\mathrm{h})$ & 15 & 8 & - & 15 \\
\hline Forklifts, food start time (h) & 5 & 5 & - & 5 \\
\hline Estimation error (\%) & $3.7 \%$ & $8.94 \%$ & $13.21 \%$ & $3.63 \%$ \\
\hline
\end{tabular}

${ }^{1}$ Block-cutting starts from 8 a.m. on Saturdays.

Considering summer load curves values, new constraints were formed, and new optimum values were calculated.

The figures and tables below show load curves and optimum variables for fall and winter.

It is worth mentioning that Friday's load resulted mostly from the constant load of the food industry and the glass industry's melting process. This paper assumes that the melting process demands the same amount of electricity as on weekdays. However, it may be less due to a decrease in temperature because there is no production on Fridays. There are not enough data to estimate the decreased temperature, but this may be the reason for a higher estimation error for Fridays.

Differences seasonal industry factors may have resulted from different market demands and the high price of storage or other factors that are out of this paper's scope. However, in other studies, this information may play a key role in strategic planning in the energy industry. Moreover, the different start times for processes in different seasons and days of the week may be a lead for other forms of energy and water usage pattern estimations.

\section{Discussion and Conclusions}

As mentioned in the introduction, industrial load monitoring is less addressed than domestic and commercial load monitoring. Some challenges make it a complex problem, including the interlock between energy consumption and manpower, different equipment types in different industries, adjusted power factor, industrial secrecy, and limited availability of detailed data.

A new method was proposed for clustering industries into three groups, and then the load curve estimation for each one was discussed. An algorithm was introduced to disaggregate the total load curve to process load curves. A case study of an industrial zone load was studied in detail, and the results showed less than $5 \%$ error on weekdays, which is impressive considering the little available data. For other days, with fewer data, estimation error increased, whereby the estimated load curve never fit the actual load curve completely as there were processes that did not start at the beginning of the sample time steps and other assumptions mentioned in Section 1. The method's accuracy increased with more available data, but still gave acceptable results with limited data. As an NILM method, this method may be used for DSM programmes, leading to reduced electricity costs and increased reliability for customers while increasing the grid's efficiency and security. It can also help providers at bulk points to plan and operate energy systems comprehensively. This method is a process-based one that provides data for other forms of energy consumption. Industrial zone management teams may use this methodology for cheap, quick, and accurate assessments in their energy management project feasibility assessment studies before any huge investment. Moreover, energy field policymakers may utilise this method to identify the priority of policy changing projects. 
This paper used energy consumption-material production and energy consumptionmanpower links as beneficial data to develop a method overcoming other industrial load disaggregation challenges. This method avoids using reactive power; thus, in cases where reactive power usage data are unavailable or defective due to industrial load factor adjustment, it is still functional. Moreover, the lack of installed sensors or industrial owners' unwillingness to share data or fill diaries does not disable the functionality of this method, although it creates some challenges. For instance, low-resolution data at bulk points can increase the estimation error, while there may be a need for process studies for other industries.

Generally speaking, this method may be used in all countries and industries. The main industrial processes in the case study should be recognised and studied (the same industry's processes may be different in higher- or lower-income countries). However, if there is high diversity in the factories in an industrial park, this method is not functional. In this case, several processes with the same duration and power range can lead to false data. If there are higher-resolution data available, the number of industries may be increased.

Furthermore, while this method is a powerful tool in load monitoring, as the first step in any DSM programme, the limits in utilising this method should be considered for some DSM programmes such as load shifting. As discussed with regard to the challenge of industrial loads, there is an interlock between energy flow and material flow in the industrial sector and an interlock between manpower and processes. The latter was mildly addressed, but the material interlock remains untouched. Load shifting faces limits and should be optimised, considering cost or even the possibility of raw and intermediate material storage. These elements were not the focus of this paper, but are important in DSM programmes.

Author Contributions: Conceptualization, S.T.; methodology, S.T.; software, S.T.; validation, S.T.; formal analysis, S.T.; investigation, S.T.; writing —original draft preparation, S.T.; writing — review and editing, K.K.; supervision, K.K. All authors read and agreed to the published version of the manuscript.

Funding: This research received no external funding.

Institutional Review Board Statement: Not applicable.

Informed Consent Statement: Not applicable.

Data Availability Statement: Restrictions apply to the availability of these data. Data were obtained from the Iran Grid Management Company and are available from the authors with the permission of the Iran Grid Management Company.

Conflicts of Interest: The authors declare no conflict of interest.

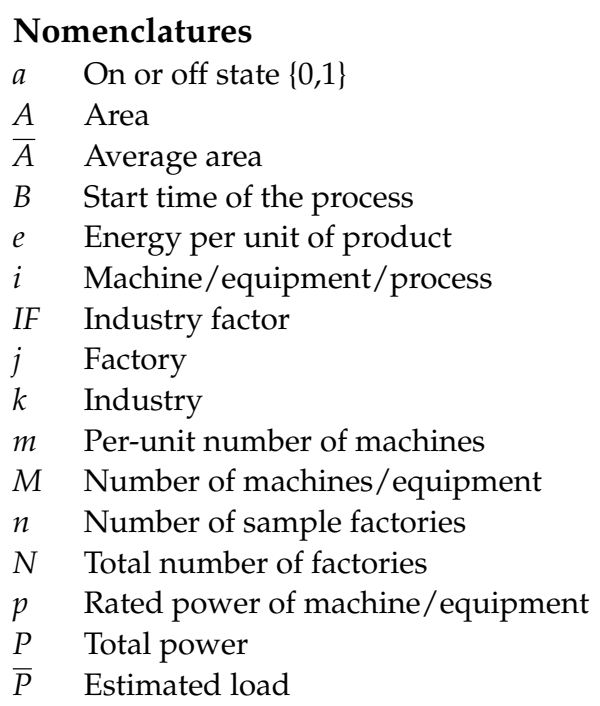




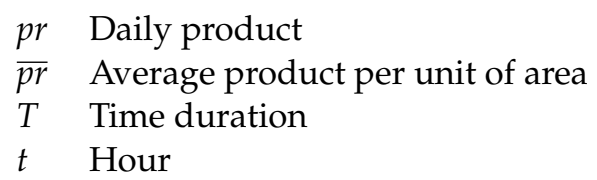

\section{References}

1. Zhao, L.; Zhou, Y.; Quilumba, F.L.; Lee, W.J. Potential of the Commercial Sector to Participate in the Demand Side Management Program. In Proceedings of the IEEE Transactions on Industry Applications; Institute of Electrical and Electronics Engineers Inc.: Piscataway, NJ, USA, 26 August, 2019; Volume 55, pp. 7261-7269. [CrossRef]

2. Zhang, Q.; Grossmann, I.E. Enterprise-wide optimization for industrial demand side management: Fundamentals, advances, and perspectives. Chem. Eng. Res. Des. 2016, 116, 114-131. [CrossRef]

3. Company, Iran Grid Management Report on the Status of the Country's Electricity Transmission Network. 2020.

4. Strbac, G. Demand side management: Benefits and challenges. Energy Policy 2008, 36, 4419-4426. [CrossRef]

5. Zhang, Q.; Grossmann, I.E. Planning and scheduling for industrial demand side management: Advances and challenges. In Alternative Energy Sources and Technologies: Process Design and Operation; Springer International Publishing: New York, NY, USA, 2016; pp. 383-414. ISBN 9783319287522.

6. Khan, I.; Jack, M.W.; Stephenson, J. Dominant factors for targeted demand side management-An alternate approach for residential demand profiling in developing countries. Sustain. Cities Soc. 2021, 67, 102693. [CrossRef]

7. Tawalbeh, N.; Abusamaha, H.M.; Al-Salaymeh, A. Demand side management and its possibilities in jordan. J. Ecol. Eng. 2020, 21, 29-33. [CrossRef]

8. Samad, T.; Kiliccote, S. Smart grid technologies and applications for the industrial sector. Comput. Chem. Eng. 2012, 47, 76-84. [CrossRef]

9. Adabi, A.; Mantey, P.; Holmegaard, E.; Kjaergaard, M.B. Status and challenges of residential and industrial non-intrusive load monitoring. In Proceedings of the 2015 IEEE Conference on Technologies for Sustainability, SusTech 2015, Ogden, UT, USA, 30 July-1 August 2015; Institute of Electrical and Electronics Engineers Inc.: Piscataway, NJ, USA, 2015; pp. 181-188. [CrossRef]

10. Cardoso, C.A.; Torriti, J.; Lorincz, M. Making demand side response happen: A review of barriers in commercial and public organisations. Energy Res. Soc. Sci. 2020, 64, 101443. [CrossRef]

11. Castro, P.M.; Ave, G.D.; Engell, S.; Grossmann, I.E.; Harjunkoski, I. Industrial Demand Side Management of a Steel Plant Considering Alternative Power Modes and Electrode Replacement. Ind. Eng. Chem. Res. 2020, 59, 13642-13656. [CrossRef]

12. Gaur, M.; Majumdar, A. Disaggregating transform learning for non-intrusive load monitoring. IEEE Access 2018, 6, 46256-46265. [CrossRef]

13. Hart, G.W. Nonintrusive Appliance Load Monitoring. Proc. IEEE 1992, 80, 1870-1891. [CrossRef]

14. Norford, L.K.; Leeb, S.B. Non-intrusive electrical load monitoring in commercial buildings based on steady-state and transient load-detection algorithms. Energy Build. 1996, 24, 51-64. [CrossRef]

15. Farinaccio, L.; Zmeureanu, R. Using a pattern recognition approach to disaggregate the total electricity consumption in a house into the major end-uses. Energy Build. 1999, 30, 245-259. [CrossRef]

16. Chang, H.H.; Chen, K.L.; Tsai, Y.P.; Lee, W.J. A new measurement method for power signatures of nonintrusive demand monitoring and load identification. In Proceedings of the IEEE Transactions on Industry Applications; IEEE: Piscataway, NJ, USA, 2012; Volume 48, pp. 764-771.

17. Liang, J.; Ng, S.K.K.; Kendall, G.; Cheng, J.W.M. Load signature studypart I: Basic concept, structure, and methodology IEEE Trans. Power Deliv. 2010, 25, 551-560. [CrossRef]

18. Devlin, M.A.; Hayes, B.P. Load identification and classification of activities of daily living using residential smart meter data. In Proceedings of the 2019 IEEE Milan PowerTech, PowerTech 2019, Politecnico di Milano, Milan, Italy, 23-27 June 2019; Institute of Electrical and Electronics Engineers Inc.: Piscataway, NJ, USA, 2019. [CrossRef]

19. Baranski, M.; Voss, J. Genetic algorithm for pattern detection in NIALM systems. In Proceedings of the International Conference on Systems, Man and Cybernetics, Hague, The Netherlands, 10-13 October 2004; Volume 4, pp. 3462-3468.

20. Suzuki, K.; Inagaki, S.; Suzuki, T.; Nakamura, H.; Ito, K. Nonintrusive appliance load monitoring based on integer programming In Proceedings of the SICE Annual Conference, Tokyo, Japan, 20-22 August 2008; pp. 2742-2747.

21. Liang, J.; Ng, S.K.K.; Kendall, G.; Cheng, J.W.M. Load signature studypart II: Disaggregation framework, simulation, and applications. IEEE Trans. Power Deliv. 2010, 25, 561-569. [CrossRef]

22. Green, D.H.; Shaw, S.R.; Lindahl, P.; Kane, T.J.; Donnal, J.S.; Leeb, S.B. A MultiScale Framework for Nonintrusive Load Identification. IEEE Trans. Ind. Inform. 2020, 16, 992-1002. [CrossRef]

23. Zeifman, M.; Roth, K. Disaggregation of home energy display data using probabilistic approach. In Proceedings of the Digest of Technical Papers-IEEE International Conference on Consumer Electronics, Las Vegas, NV, USA, 12-15 January 2012; pp. 630-631. [CrossRef]

24. Zoha, A.; Gluhak, A.; Imran, M.; Rajasegarar, S. Non-Intrusive Load Monitoring Approaches for Disaggregated Energy Sensing: A Survey. Sensors 2012, 12, 16838-16866. [CrossRef]

25. Esa, N.F.; Abdullah, M.P.; Hassan, M.Y. A review disaggregation method in Non-intrusive Appliance Load Monitoring. Renew. Sustain. Energy Rev. 2016, 66, 163-173. [CrossRef] 
26. Carrie Armel, K.; Gupta, A.; Shrimali, G.; Albert, A. Is disaggregation the holy grail of energy efficiency? The case of electricity. Energy Policy 2013, 52, 213-234. [CrossRef]

27. Batra, N.; Parson, O.; Berges, M.; Singh, A.; Rogers, A. A Comparison of Non-Intrusive Load Monitoring Methods for Commercial and Residential Buildings. August 2014. Available online: http:/ /arxiv.org/abs/1408.6595 (accessed on 24 December 2020).

28. Laughman, C.; Lee, K.; Cox, R.; Shaw, S.; Leeb, S.; Norford, L.; Armstrong, P. Power signature analysis. IEEE Power Energy Mag. 2003, 1, 56-63. [CrossRef]

29. Chang, H.H.; Yang, H.T.; Lin, C.L. Load identification in neural networks for a non-intrusive monitoring of industrial electrical loads. In Proceedings of the Lecture Notes in Computer Science (Including Subseries Lecture Notes in Artificial Intelligence and Lecture Notes in Bioinformatics), Karlsruhe, Germany, 15-17 September 2008; Springer: Berlin/Heidelberg, Germany, 2008; Volume 5236, pp. 664-674. [CrossRef]

30. Martins, P.B.M.; Gomes, J.G.R.C.; Nascimento, V.B.; De Freitas, A.R. Application of a Deep Learning Generative Model to Load Disaggregation for Industrial Machinery Power Consumption Monitoring. In Proceedings of the 2018 IEEE International Conference on Communications, Control, and Computing Technologies for Smart Grids (SmartGridComm), Aalborg, Denmark, 29-31 October 2018. [CrossRef]

31. Brucke, K.; Arens, S.; Telle, J.-S.; Von Maydell, K.; Agert, C. Particle Swarm Optimization for Energy Disaggregation in Industrial and Commercial Buildings. arXiv 2020, arXiv:2006.12940.

32. Yang, F.; Liu, B.; Luan, W.; Zhao, B.; Liu, Z.; Xiao, X.; Zhang, R. FHMM Based Industrial Load Disaggregation. In Proceedings of the 2021 6th Asia Conference on Power and Electrical Engineering (ACPEE), Chongqing, China, 8-11 April 2021; pp. 330-334. [CrossRef]

33. Yang, M. Demand side management in Nepal. Energy 2006, 31, 2677-2698. [CrossRef]

34. Paulus, M.; Borggrefe, F. The potential of demand-side management in energy-intensive industries for electricity markets in Germany. Appl. Energy 2011, 88, 432-441. [CrossRef]

35. Harish, V.S.K.V.; Kumar, A. Demand side management in India: Action plan, policies and regulations. Renew. Sustain. Energy Rev. 2014, 33, 613-624. [CrossRef]

36. Warren, P. A review of demand-side management policy in the UK. Renew. Sustain. Energy Rev. 2014, 29, 941-951. [CrossRef]

37. Alasseri, R.; Tripathi, A.; Joji Rao, T.; Sreekanth, K.J. A review on implementation strategies for demand side management (DSM) in Kuwait through incentive-based demand response programs. Renew. Sustain. Energy Rev. 2017, 77, 617-635. [CrossRef]

38. Omar, S.A.S. Kuwait Energy Outlook. 2019. Available online: https://www.undp.org/content/dam/rbas/doc/Energy\%20and\% 20Environment/KEO_report_English.pdf (accessed on 6 August 2021).

39. Zhang, S.; Jiao, Y.; Chen, W. Demand-side management (DSM) in the context of China's on-going power sector reform. Energy Policy 2017, 100, 1-8. [CrossRef]

40. IEA. Demand Response; IEA: Paris, France, 2020; Available online: https:/ / www.iea.org/reports/demand-response (accessed on 6 August 2021).

41. Ding, Y.M.; Hong, S.H.; Li, X.H. A demand response energy management scheme for industrial facilities in smart grid. IEEE Trans. Ind. Inform. 2014, 10, 2257-2269. [CrossRef]

42. Xu, Y.; Milanović, J.V. Artificial-intelligence-based methodology for load disaggregation at bulk supply point. IEEE Trans. Power Syst. 2015, 30, 795-803. [CrossRef]

43. Cominola, A.; Giuliani, M.; Piga, D.; Castelletti, A.; Rizzoli, A.E. A Hybrid Signature-based Iterative Disaggregation algorithm for Non-Intrusive Load Monitoring. Appl. Energy 2017, 185, 331-344. [CrossRef]

44. He, K.; Stankovic, L.; Liao, J.; Stankovic, V. Non-Intrusive Load Disaggregation Using Graph Signal Processing. IEEE Trans. Smart Grid 2018, 9, 1739-1747. [CrossRef]

45. Hock, D.; Kappes, M.; Ghita, B. Non-Intrusive Appliance Load Monitoring using Genetic Algorithms. In Proceedings of the IOP Conference Series: Materials Science and Engineering, Kuala Lumpur, Malaysia, 13-14 August 2018; Institute of Physics Publishing: Bristol, UK, 2018; Volume 366, p. 012003. [CrossRef]

46. Zeifman, M.; Roth, K. Nonintrusive appliance load monitoring: Review and outlook. IEEE Trans. Consum. Electron. 2011, 57, 76-84. [CrossRef]

47. Figueiredo, M.; de Almeida, A.; Ribeiro, B. Home electrical signal disaggregation for non-intrusive load monitoring (NILM) systems. Neurocomputing 2012, 96, 66-73. [CrossRef]

48. Belley, C.; Gaboury, S.; Bouchard, B.; Bouzouane, A. An efficient and inexpensive method for activity recognition within a smart home based on load signatures of appliances. In Proceedings of the Pervasive and Mobile Computing; Elsevier B.V.: Amsterdam, The Netherlands, 2014; Volume 12, pp. 58-78. [CrossRef]

49. Deb, C.; Frei, M.; Hofer, J.; Schlueter, A. Automated load disaggregation for residences with electrical resistance heating. Energy Build. 2019, 182, 61-74. [CrossRef]

50. Patel, S.N.; Robertson, T.; Kientz, J.A.; Reynolds, M.S.; Abowd, G.D. At the Flick of a Switch: Detecting and Classifying Unique Electrical Events on the Residential Power Line (Nominated for the Best Paper Award). In UbiComp 2007: Ubiquitous Computing; Springer: Berlin/Heidelberg, Germany, 2007; pp. 271-288.

51. Mohseni, S.; Haratian, M. Energy audit and estimation of electricity consumption criteria in stone cutting plants. In Proceedings of the 24th Power System Conference, Tehran, Iran, 16 November 2009; Available online: https://civilica.com/doc/89372/ (accessed on 6 August 2021). 
52. Gharechahi, H.; Askari, M. Design of energy consumption optimization system for stonecutting plants' polishing machines. In Proceedings of the National Conference of Mechanical Engineering Iran, Shiraz, Iran, 27 February 2014; Available online: https:/ / civilica.com/doc/247819/ (accessed on 6 August 2021).

53. Ruth, M.; Dell'Anno, P. An industrial ecology of the US glass industry. Resour. Policy 1997, 23, 109-124. [CrossRef]

54. Lawrence, A.; Thollander, P.; Andrei, M.; Karlsson, M. Specific Energy Consumption/Use (SEC) in Energy Management for Improving Energy Efficiency in Industry: Meaning, Usage and Differences. Energies 2019, 12, 247. [CrossRef]

55. Glass the industry of future 2002. Available online: https:/ / www.nrel.gov/docs/fy02osti/32135.pdf (accessed on 24 December 2020).

56. Manufacturing Energy and Carbon Footprints (2014 MECS. Department of Energy. Available online: https:/ / www.energy.gov/ eere/amo/manufacturing-energy-and-carbon-footprints-2014-mecs (accessed on 24 December 2020). 